\title{
Optimal Velocity Control for a Battery Electric Vehicle Driven by Permanent Magnet Synchronous Motors
}

\author{
Dongbin Lu, Minggao Ouyang, Jing Gu, and Jianqiu Li \\ State Key Laboratory of Automotive Safety and Energy, Tsinghua University, Beijing 100084, China \\ Correspondence should be addressed to Minggao Ouyang; ouymg@tsinghua.edu.cn
}

Received 3 June 2014; Revised 23 August 2014; Accepted 25 September 2014; Published 3 November 2014

Academic Editor: Kui Fu Chen

Copyright (C) 2014 Dongbin Lu et al. This is an open access article distributed under the Creative Commons Attribution License, which permits unrestricted use, distribution, and reproduction in any medium, provided the original work is properly cited.

\begin{abstract}
The permanent magnet synchronous motor (PMSM) has high efficiency and high torque density. Field oriented control (FOC) is usually used in the motor to achieve maximum efficiency control. In the electric vehicle (EV) application, the PMSM efficiency model, combined with the EV and road load system model, is used to study the optimal energy-saving control strategy, which is significant for the economic operation of EVs. With the help of GPS, IMU, and other information technologies, the road conditions can be measured in advance. Based on this information, the optimal velocity of the EV driven by PMSM can be obtained through the analytical algorithm according to the efficiency model of PMSM and the vehicle dynamic model in simple road conditions. In complex road conditions, considering the dynamic characteristics, the economic operating velocity trajectory of the EV can be obtained through the dynamic programming (DP) algorithm. Simulation and experimental results show that the minimum energy consumption and global energy optimization can be achieved when the EV operates in the economic operation area.
\end{abstract}

\section{Introduction}

The permanent magnet synchronous motor (PMSM) has high efficiency and high torque density and is widely used in servo, wind power, and electric vehicle applications. Field oriented control (FOC) or vector control is used in PMSM, and the maximum toque/current control can be achieved. The optimal efficiency of PMSM has been previously studied [1-4]. In many applications, the PMSM and its load constitute a system. Considering the load characteristics, how to achieve the optimal control performance of the system has rarely been reported. In this paper, the optimal control algorithm for the system is proposed and used in a battery electric vehicle (EV), especially in automatic cruise conditions.

The battery is the only energy source in the EV. The study of the minimum energy consumption control strategy is of great significance due to the limitations of battery energy. With the development of information technology and sensor technology, road condition information can be obtained more accurately, which provides the basic conditions for the global energy optimization of the EV. Global optimization is needed to minimize the power loss based on the characteristics of the entire driving cycle. The dynamic process of the system state in the optimization algorithm is taken into account, and the greatest optimal potential is obtained. There are several methods for solving the global optimization problems, such as the dynamic programming (DP) method [5, 6], the offline optimization algorithm based on neural network and genetic algorithm [7], and the iterative algorithm based on optimal control theory [8]. Among them, the DP algorithm has been applied in hybrid electric vehicles because it is simple and easy to understand [5]. A lookahead control for heavy trucks to minimize trip time and fuel consumption is presented in [9]. A dynamic programming algorithm is devised and used in a predictive control scheme by constantly feeding the conventional cruise controller with new set points. The velocity trajectory optimization in hybrid electric trucks has been proposed in [10]. Taking advantage of satellite navigation, together with the vehicle's current mass and road load parameters, an optimization velocity is formulated and solved for a driver-defined time constraint. In this paper, the analytical and DP algorithms of minimum energy consumption are explored to solve the velocity optimization of an EV driven by PMSM. 


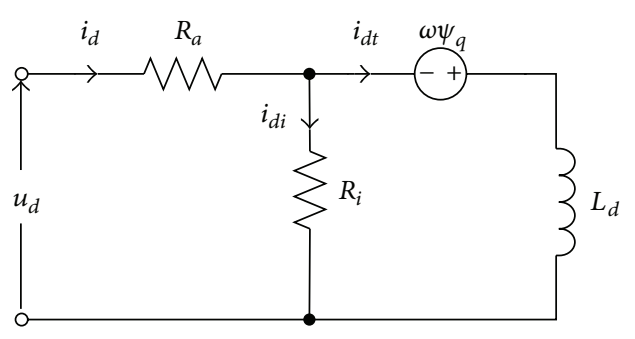

(a)

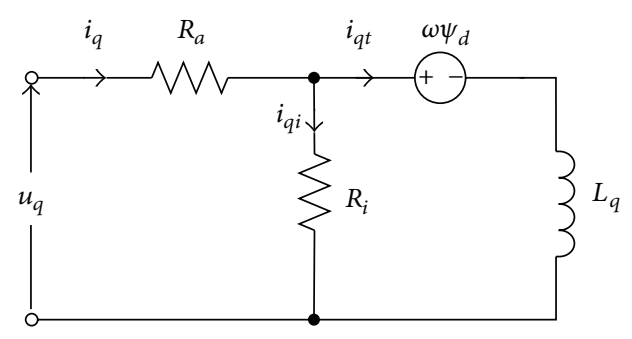

(b)

FIGURE 1: The efficiency model of the PMSM. (a) $d$-axis equivalent circuit. (b) $q$-axis equivalent circuit.

The dynamic characteristics in the minimum energy consumption control strategy for EV can be accurately acquired by the DP algorithm, but the solving process is complex and time-consuming. An analytical algorithm to solve the minimum energy consumption problem under different road loads is proposed and compared with the DP algorithm. It proved that the analytical algorithm can satisfy the engineering applications. The economic operating velocities for the $\mathrm{EV}$ in simple road conditions and complex road conditions solved by the DP algorithm are studied. Then, the economy operating states for the EV under different speed and time constraints in complex road conditions are analyzed. Finally, the energy-optimal driving velocity reference is provided for the driver to minimize the battery energy and maximize vehicle mileage.

The paper is organized as follows. Section 2 presents the vehicle and electric drive system model. The optimal velocity curves in simple road conditions calculated by the analytical model are described in Section 3. Then, the optimal velocity curves without constraint, with velocity constraint, and with time constraint in complex road conditions are studied and compared in Section 4. Simulation results and experiment validation analysis are discussed in Section 5. Section 6 presents the conclusions.

\section{Dynamics Modeling}

2.1. Vehicle Resistance Equation. The force needed when driving on a sloped road in an EV can be expressed as [11]

$$
\frac{T_{t q} i_{g} i_{0} \eta_{T}}{r}=m g f \cos \alpha+\frac{1}{2} C_{D} \rho A v^{2}+m g \sin \alpha+\delta m \frac{\mathrm{d} v}{\mathrm{~d} t},
$$

where $T_{t q}$ is the motor output torque; $i_{g}$ is the ratio of the transmission; $i_{0}$ is the ratio of the reducer; $\eta_{T}$ is the efficiency of the transmission system; $r$ is the wheel radius; $m$ is the mass of the vehicle and payload; $f$ is the rolling resistance coefficient; $\alpha$ is the slope angle; $C_{D}$ is the dimensionless coefficient; $A$ is the cross-sectional area exposed to flow; $v$ is the vehicle velocity; $\delta$ is the vehicle rotating mass conversion factor, which is involved in the determination of the added mass moment of the rotating part in the acceleration resistance; $\mathrm{d} v / \mathrm{d} t$ is the vehicle acceleration; and $\rho$ is the air density and is equal to $1.2258 \mathrm{~N} \cdot \mathrm{s}^{2} \cdot \mathrm{m}^{-4}$.
2.2. Efficiency Model of PMSM. The PMSM is a rotating electric machine where the stator is a classic three-phase stator like that of an induction motor and the rotor has surface-mounted or interior permanent magnets. A PMSM is driven by sine wave voltage coupled with the given rotor position. The generated stator flux together with the rotor flux, which is generated by a rotor magnet, defines the torque and thus speed of the motor. When the motor is running, it has four kinds of watts losses: the copper loss, the iron loss, the mechanical loss, and the stray loss.

Considering the iron loss, the $d$ - and $q$-axis equivalent circuit model of PMSM $[12,13]$ is shown in Figure 1. The $d$ axis stator current $i_{d}$ and $q$-axis stator current $i_{q}$ are divided by the iron loss currents $i_{d i}, i_{q i}$ and the torque currents $i_{d t}, i_{q t}$. In the steady-state case, the voltage balance equation can be expressed as

$$
\begin{aligned}
& u_{d}=R_{a} i_{d}-\omega \psi_{q}, \\
& u_{q}=R_{a} i_{q}+\omega \psi_{d} .
\end{aligned}
$$

The flux equation can be expressed as

$$
\begin{gathered}
\psi_{d}=L_{d} i_{d t}+\psi_{f}, \\
\psi_{q}=L_{q} i_{q t} .
\end{gathered}
$$

The electromagnetic torque equation is

$$
T_{e}=p\left(\psi_{d} i_{q t}-\psi_{q} i_{d t}\right)=p\left[\psi_{f} i_{q t}+\left(L_{d}-L_{q}\right) \mathrm{i}_{d t} i_{q t}\right]
$$

where $u_{d}$ and $u_{q}$ are the $d$ - and $q$-axis terminal voltages, respectively; $i_{d}$ and $i_{q}$ are the $d$ - and $q$-axis armature currents, respectively; $i_{d i}$ and $i_{q i}$ are the equivalent $d$ - and $q$-axis iron loss currents, respectively; $i_{d t}$ and $i_{q t}$ are the equivalent $d$ - and $q$-axis torque currents, respectively; $\psi_{d}$ and $\psi_{q}$ are the $d$ - and $q$-axis stator flux-linkages, respectively; $\psi_{f}$ is the magnet fluxlinkage; and $L_{d}$ and $L_{q}$ are the $d$ - and $q$-axis inductances, respectively. $\omega$ is the electrical angular velocity, $R_{a}$ is the armature resistance, and $p$ is the number of pole pairs.

The surface-mounted permanent magnet synchronous motor (SPMSM) will be studied in this paper, and the method is also adapted to study the interior PMSM (IPMSM) and induction motor (IM). In the SPMSM, the $d$-axis inductance is approximately equal to the $q$-axis inductance. Assuming $L_{d}=L_{q}=L$, the torque equation can be simplified as (5). 


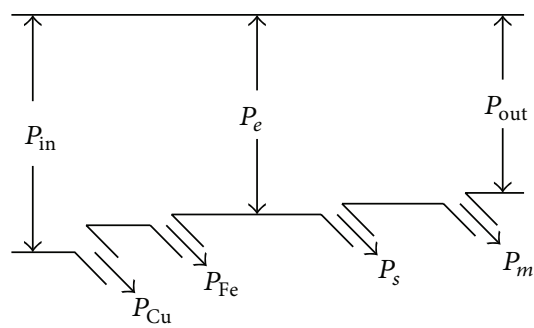

Figure 2: Power flow diagram of the PMSM.

The torque generated by the SPMSM is proportional to the $q$ axis current and has no relationship with the $d$-axis current:

$$
T_{e}=p\left(\psi_{d} i_{q t}-\psi_{q} i_{d t}\right)=p \psi_{f} i_{q t} .
$$

Figure 2 is the power flow diagram of the PMSM in driving mode. The input power of the PMSM can be deduced from (2) and (3) and the efficiency model in Figure 1 and is expressed as

$$
\begin{aligned}
P_{\text {in }} & =u_{d} i_{d}+u_{q} i_{q}=\left(R_{a} i_{d}-\omega \psi_{q}\right) i_{d}+\left(R_{a} i_{q}+\omega \psi_{d}\right) i_{q} \\
& =R_{a}\left(i_{d}^{2}+i_{q}^{2}\right)+\frac{\omega^{2}\left(\psi_{d}^{2}+\psi_{q}^{2}\right)}{R_{i}}+\omega \psi_{f} i_{q t},
\end{aligned}
$$

where $P_{\text {in }}$ is the input power and $R_{i}$ is the equivalent iron consumption resistance, which can be obtained by experiment [13]. In the right side of the equation, the first part is the copper loss $P_{\mathrm{Cu}}$, the second part is the iron loss $P_{\mathrm{Fe}}$, and the third part is the electromagnetic power $P_{e}$. The electromagnetic power, which is the sum of the mechanical loss $P_{m}$, stray loss $P_{s}$, and output power $P_{\text {out }}$, can be expressed as

$$
\omega \psi_{f} i_{q t}=P_{m}+P_{s}+P_{\text {out }} .
$$

The maximum torque/current control can be realized by controlling the $d$-axis current $i_{d}=0$ for the SPMSM, which is applied to the traction motor of this paper.

According to the equivalent circuit and formulas (2)-(6), the relations of power loss, electromagnetic torque, and the electric angular velocity can be expressed as

$$
P_{\mathrm{Cu}}=R_{a}\left[\left(\frac{\omega^{2} L^{2}}{R_{i}^{2}}+1\right) \cdot \frac{T_{e}}{p \psi_{f}}+\frac{\omega \psi_{f}}{R_{i}}\right]^{2},
$$

$P_{\text {Fe }}$

$$
=\frac{\omega^{2}\left[\left(\left(\omega L^{2} / R_{i}\right) \cdot\left(T_{e} / p \psi_{f}\right)+\psi_{f}\right)^{2}+\left(L \cdot\left(T_{e} / p \psi_{f}\right)\right)^{2}\right]}{R_{i}} .
$$

The input power can be deduced as

$$
\begin{aligned}
& P_{\text {in }} \\
& =T_{e} \cdot \frac{\omega}{p}+R_{a}\left[\left(\frac{\omega^{2} L^{2}}{R_{i}^{2}}+1\right) \cdot \frac{T_{e}}{p \psi_{f}}+\frac{\omega \psi_{f}}{R_{i}}\right]^{2} \\
& \quad+\frac{\omega^{2}\left[\left(\left(\omega L^{2} / R_{i}\right) \cdot\left(T_{e} / p \psi_{f}\right)+\psi_{f}\right)^{2}+\left(L \cdot\left(T_{e} / p \psi_{f}\right)\right)^{2}\right]}{R_{i}} .
\end{aligned}
$$

The maximum electromagnetic torque of the PMSM in driving mode needs to satisfy the following conditions:

$$
T_{\text {edm }}= \begin{cases}T_{e \max }, & \text { if } P_{e} \leq P_{e n} \\ \frac{P_{e n}}{\omega} p, & \text { if } P_{e}>P_{e n}\end{cases}
$$

The available maximum electromagnetic torque in regenerative braking mode must satisfy the conditions

$$
T_{\text {ebm }}= \begin{cases}-\frac{\omega \psi_{f}^{2}}{R_{l}} p & \\ -T_{e \max }, & \text { if } T_{\text {ebrk }} \leq-T_{e \max } \\ -\frac{P_{e n}}{\omega} p, & \text { if } P_{e}<-P_{e n} .\end{cases}
$$

According to the model of the PMSM, field oriented control (FOC) is used in the motor to achieve maximum control efficiency. In field oriented control, the stator phase currents are measured and converted into a corresponding complex vector. This current vector is then transformed to a coordinate system rotating with the rotor of the machine. Now the real $x$-axis component of the stator current vector $\left(i_{d}\right)$ in this rotor flux oriented coordinate system can be used to control the rotor flux-linkage and the imaginary $y$-axis component $\left(i_{q}\right)$ can be used to control the motor torque.

2.3. Efficiency Model of the Inverter. To accurately evaluate the inverter efficiency, one must have well-developed component models and an inverter switching algorithm. Otherwise, an accurate evaluation can only be obtained by actual tests. However, by making some assumptions and simplifying the device models, the analytical model can be applied to the inverter efficiency evaluation [14-16]. For conduction loss evaluation, a simplified device model is employed: a pure resistor for power MOSFETs and a voltage source in series with a resistor for insulated gate bipolar transistors (IGBTs) and diodes. In this paper, the loss of a three-phase MOSFET-based full-bridge inverter is discussed, and the space vector pulse width modulation (SVPWM) is adopted by this inverter. 
The conduction losses for the MOSFET and the antiparallel diode are shown in (12), respectively. The detailed derivation of the equation can be found in [17]:

$$
\begin{aligned}
P_{c-\text { MOSFTET }}=I_{m}^{2} R_{d s}\left(\frac{1}{8}+\frac{m_{i}}{3 \pi} \cos \varphi\right), \\
P_{c-D}=\frac{1}{2} I_{m} V_{f}\left(\frac{1}{\pi}-\frac{m_{i}}{4} \cos \varphi\right) \\
+I_{m}^{2} R_{a k}\left(\frac{1}{8}-\frac{m_{i}}{3 \pi} \cos \varphi\right),
\end{aligned}
$$

where $V_{d s}$ and $V_{a k}$ represent the on-state voltage drops of MOSFET and diode, respectively; $V_{f}$ is the diode voltage drop at the zero-current condition; $R_{d s}$ and $R_{a k}$ are the resistive elements of MOSFET and the diode; $I$ is the device current; and $m_{i}$ is the per unit fundamental stator voltage, $\varphi$ is the load power factor angle, and $I_{m}$ is the peak value of the sinusoidal wave.

Considering the dead time effect, the conduction loss of the MOSFETs and the antiparallel diodes in the three-phase inverter can be simplified as

$$
\begin{aligned}
& P_{c-\text { MOSFETs }}=\frac{3}{2} I_{m}^{2} R_{d s}\left(1-\frac{2 t_{d}}{t_{c}}\right), \\
& P_{c-D s}=\left(\frac{6}{\pi} V_{f} I_{m}+\frac{3}{2} I_{m}^{2} R_{a k}\right) \frac{2 t_{d}}{t_{c}},
\end{aligned}
$$

where $t_{d}$ is the dead time and $t_{c}$ is the period time of the SVPWM.

The conduction loss of the inverter is

$$
P_{c}=P_{c-\text { MOSFETs }}+P_{c-D s} .
$$

The switching loss of the three-phase inverter is

$$
P_{\text {sw }}=3\left(P_{\text {sw-on }}+P_{\text {sw-off }}\right)
$$

where $P_{\text {sw-on }}$ and $P_{\text {sw-off }}$ are the turn-on loss and the turn-off loss, respectively.

The total loss of the three-phase inverter, which is the sum of the conduction loss and the switching loss, can be expressed as

$$
\begin{aligned}
P_{\mathrm{inv}}= & P_{c}+P_{\mathrm{sw}} \\
= & \left(\frac{12 t_{d} V_{f}}{\pi t_{c}}+\frac{3 k_{\mathrm{on}} f_{s}}{\pi}+\frac{3 k_{\mathrm{off}} f_{s}}{\pi}\right) I_{m} \\
& +\left[\frac{3 R_{a k} t_{d}}{t_{c}}+\frac{3}{2} R_{d s}\left(1-\frac{2 t_{d}}{t_{c}}\right)\right] I_{m}^{2},
\end{aligned}
$$

where the relationship between $I_{m}$ and $i_{q}, T_{e}$ is as follows:

$$
I_{m}=\sqrt{\frac{2}{3}} \cdot i_{q}=\sqrt{\frac{2}{3}} \cdot\left[\left(\frac{\omega^{2} L^{2}}{R_{i}^{2}}+1\right) \cdot \frac{T_{e}}{p \psi_{f}}+\frac{\omega \psi_{f}}{R_{i}}\right] .
$$

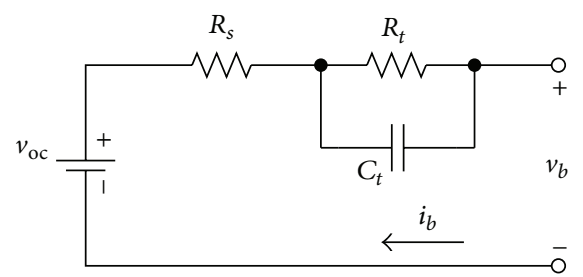

FIGURE 3: A generalized ECM for lithium batteries.

The loss of the inverter can be expressed by the electromagnetic torque and electrical angular velocity of the PMSM as

$$
\begin{aligned}
P_{\mathrm{inv}}= & \sqrt{\frac{2}{3}}\left(\frac{12 t_{d} V_{f}}{\pi t_{c}}+\frac{3 k_{\mathrm{on}} f_{s}}{\pi}+\frac{3 k_{\mathrm{off}} f_{s}}{\pi}\right) \\
& \cdot\left[\left(\frac{\omega^{2} L^{2}}{R_{i}^{2}}+1\right) \cdot \frac{T_{e}}{p \psi_{f}}+\frac{\omega \psi_{f}}{R_{i}}\right] \\
& +\left[\frac{2 R_{a k} t_{d}}{t_{c}}+R_{d s}\left(1-\frac{2 t_{d}}{t_{c}}\right)\right] \\
& \cdot\left[\left(\frac{\omega^{2} L^{2}}{R_{i}^{2}}+1\right) \cdot \frac{T_{e}}{p \psi_{f}}+\frac{\omega \psi_{f}}{R_{i}}\right]^{2} .
\end{aligned}
$$

2.4. Battery Model. The electric model of the battery, which is described by a circuit that is composed of the basic elements, such as a resistor and capacitor, and is called an ECM, is widely used to analyze the dynamic properties of the battery voltage and current [18-20]. The error in analyzing the battery charge and discharge properties does not exceed 5\% [20], which satisfies the engineering requirement. Typically, the architecture of the circuit is composed of a fundamental ohmic resistor and one or more RC networks connected in series to simulate both the transient and steady responses of the battery. One of the ECMs used to simulate cell performance is illustrated in Figure 3, where an ohmic resistor with resistance $R_{s}$, an RC network $\left(R_{t} / / C_{t}\right)$, and a DC source with voltage $v_{\mathrm{oc}}(\mathrm{OCV})$ that is a function of SOC are connected in series. $v_{b}$ is defined as the battery terminal voltage and $i_{b}$ is the outflow current.

Using Kirchhoff's law, the dynamics of the ECM shown in Figure 3 can be expressed as

$$
\begin{gathered}
\dot{v}_{c}=-\frac{1}{C_{t} R_{t}} v_{c}+\frac{1}{C_{t}} i_{b}, \\
v_{b}=v_{\mathrm{oc}}-R_{s} i_{b}-v_{c},
\end{gathered}
$$

where $v_{c}$ is defined as the voltage across the RC network, as observed in Figure 3.

The energy consumption in a battery can also be expressed by the electromagnetic torque and electrical angular velocity of the PMSM as

$$
P_{b R}=\frac{\left[v_{\mathrm{oc}}-\sqrt{v_{\mathrm{oc}}^{2}-4\left(R_{s}+R_{t}\right)\left(P_{\mathrm{in}}+P_{\mathrm{inv}}\right)}\right]^{2}}{4\left(R_{s}+R_{t}\right)},
$$


where $P_{\text {in }}$ and $P_{\text {inv }}$ are functions of the electromagnetic torque and electrical angular velocity of the PMSM, respectively, as shown in (9) and (18).

\section{Optimal Velocity Curve in Simple Road Conditions}

The simple road conditions proposed in this paper mean that the rolling resistance coefficient, the air density of fluid, and the road grade angle are constant.

The economic velocity of the EV is defined as the best mileage that can be reached with the constant battery energy if the EV is traveling at this speed. Determination of the energy-time optimal velocity trajectories requires a combination of route information and vehicle conditions. If the sum of the rolling resistance force and the climbing resistance force is greater than zero, the motor works in driving mode. The optimal mileage is described by

$$
\begin{gathered}
J=\max (s), \\
\int_{0}^{t} P_{\text {bat }}(t) \mathrm{d} t=E_{d},
\end{gathered}
$$

where $P_{\text {bat }}$ is the sum of $P_{\text {in }}, P_{\text {inv }}$, and $P_{b R}$ and $E_{d}$ is the available discharged energy in the battery.

For simple road conditions, the mileage equation in driving mode is given by

$$
s=\int_{0}^{t} u_{a}(t) \mathrm{d} t=u_{a} \times \frac{E_{d}}{P_{\mathrm{in}}+P_{\mathrm{inv}}+P_{b R}}
$$

where $u_{a}$ is the velocity in $\mathrm{km} \cdot \mathrm{h}^{-1}$ and

$$
\begin{gathered}
T_{e}=\frac{r}{i_{g} i_{0} \eta_{T}}\left(G f \cos \alpha+\frac{C_{D} A}{21.15} u_{a}^{2}+G \sin \alpha\right)+T_{m}, \\
T_{e} \leq T_{\text {edm }}, \\
\omega=\frac{p i_{g} i_{0} u_{a}}{3.6 r} .
\end{gathered}
$$

In (23), if the required electromagnetic torque $T_{e}$ calculated by the driving conditions is larger than the maximum electromagnetic torque $T_{\text {edm }}$ in (10), the required electromagnetic torque is equal to the maximum electromagnetic torque.

If the sum of the rolling resistance force and the climbing resistance force is less than zero, the motor works in braking mode. The optimal mileage is defined as the battery being fully charged in the shortest mileage and is described by

$$
\begin{gathered}
J=\min (s), \\
\int_{0}^{t}-P_{\text {bat }}(t) \mathrm{d} t=E_{c}
\end{gathered}
$$

where $E_{c}$ is the available charged energy in the battery.
For simple road conditions, the mileage equation in braking mode is given by

$$
\begin{gathered}
s=\int_{0}^{t} u_{a}(t) \mathrm{d} t=u_{a} \times \frac{-E_{c}}{P_{\mathrm{in}}+P_{\mathrm{inv}}+P_{b R}}, \\
T_{e}=\frac{r}{i_{g} i_{0} \eta_{T}}\left(G f \cos \alpha+\frac{C_{D} A}{21.15} u_{a}^{2}+G \sin \alpha\right)+T_{m}, \\
T_{e} \geq T_{\mathrm{ebm}}, \\
\omega=\frac{p i_{g} i_{0} u_{a}}{3.6 r} .
\end{gathered}
$$

In (27), if the required electromagnetic torque $T_{e}$ calculated by the driving conditions is less than the negative maximum electromagnetic torque $T_{\mathrm{ebm}}$ in (11), the required electromagnetic torque equals the negative maximum electromagnetic torque.

In driving mode, the optimal velocity means that the vehicle drives the longest distance at this speed while consuming the same amount of battery energy. In braking mode, the optimal velocity means that the vehicle drives the shortest distance at this speed while recharging the same amount of battery energy.

The numerical method is used to obtain the problem solution in the analytical approach. For every velocity from 0 to the maximum one, the mileage can be calculated when the battery energy is a certain value. Comparing the mileages for every velocity, we can obtain the maximum one in driving mode and the minimum one in braking mode, which are the optimal velocities.

In driving conditions, generally, the rolling resistance coefficient and air density are constants, but the slope angle often changes. Therefore, it is important to solve the optimal velocity at different slope angles. When the battery energy is a certain value, the mileage versus the velocity curve at different slope angles in a four-wheel drive electric vehicle is shown in Figure 4. At a slope angle, the EV can drive different miles for different constant velocities. The specifications of the EV and motors used in this and the following figures can be found in Section 5.

In Figure 4, the EV consumes energy at slope angles of $0 \%, 5 \%$, and $10 \%$. The percentages are the tangent values of slope angles which equal the vertical height divided by the horizontal movement distance and then multiplied by $100 \%$. An optimal velocity can be found, and the mileage is monotonically decreasing on both sides of the optimal velocity at slope angles of $0 \%, 5 \%$, and $10 \%$. The motor recharged energy at the slope angles $-10 \%$ and $-5 \%$. An optimal velocity can also be found, and the mileage is monotonically increasing on both sides of the optimal velocity. Therefore, an optimal velocity can be found for each slope angle, as shown in Figure 5. The figure shows that the greater the slope angle, the greater the velocity in downhill braking mode and the greater the slope angle, the greater the velocity in driving mode. 


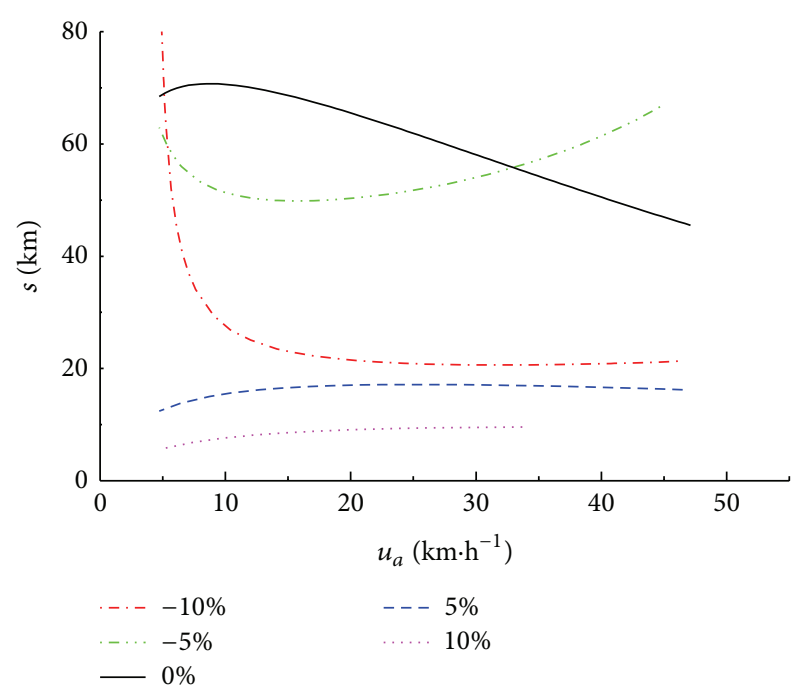

FIGURE 4: Relations between velocity and mileage at different slope angles.

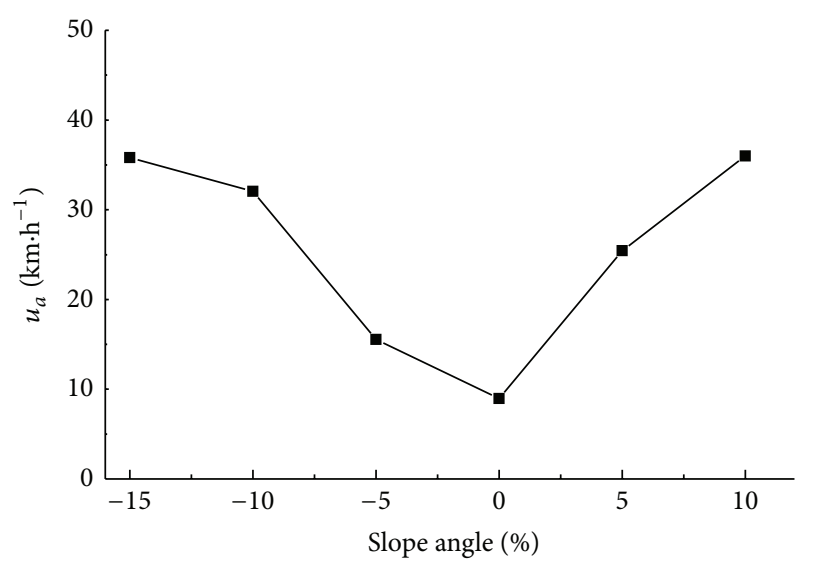

FIgURE 5: Optimal velocity at different slope angles.

\section{Optimal Velocity Curve in Complex Road Conditions}

The complex road conditions proposed in this paper mean that the road grade angle changes. The road parameters can be measured with the help of the GPS navigation system and vehicle sensors. To compare the analytical approach and dynamic programming (DP) algorithm, this paper uses longdistance segment-unchanging road conditions. The road consists of five segments, whose slope angles are $0 \%\left(s_{1}\right), 5 \%$ $\left(s_{2}\right), 0 \%\left(s_{3}\right),-5 \%\left(s_{4}\right)$, and $0 \%\left(s_{5}\right)$.

4.1. Analytical Approach for the Optimal Velocity Curve. In the above-mentioned long-distance segment-unchanging road, the optimal velocity curve can be obtained by an analytical approach. For more complex road conditions, a guide for solving the optimal velocity can be provided by an analytical approach. The optimal velocity is equivalent
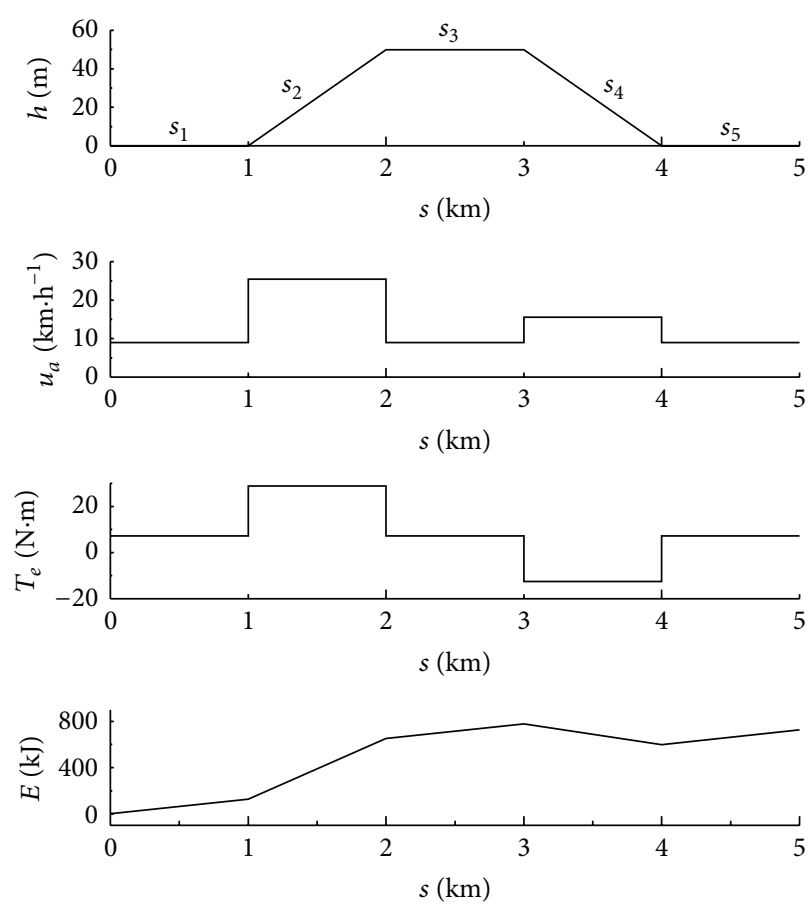

FIGURE 6: Optimal operating state for different slope angle sections.

to the least energy consumption on a particular road when travelling at a particular velocity and is described by

$$
\begin{gathered}
J=\min \left(E_{d s}-E_{c s}\right) \\
\sum_{i=1}^{n}\left(\int_{t_{i-1}}^{t_{i}} P_{\text {bat } i}(t) \mathrm{d} t\right)=E_{d s}-E_{c s}
\end{gathered}
$$

where $P_{\text {bat } i}$ is the battery power required in each segment, $E_{d s}$ is the discharged energy of the battery on the road, and $E_{c s}$ is the recharged energy of the battery on the road.

According to the analysis in Section 3, an optimal velocity can be found for each slope angle. The EV consumes the least energy when travelling on each slope angle road with the corresponding optimal velocity. For each optimal velocity, the motor operating states and the energy consumption can be obtained according to (21)-(28), as shown in Figure 6. It shows that the optimal operating velocities are different for different slope angle sections.

For different slope angles, an optimal operating point (an optimal torque and speed point) can be found in the motor efficiency map, as shown in Figure 7. The motor does not operate at the optimal efficiency point at the same speed and is under the optimal point. The reason is that the road load is considered, and high driving torque means high energy consumption.

The analytical method can accurately obtain the optimal velocity in the steady state, but it is difficult to solve the dynamic process because of the nonlinearity.

4.2. Dynamic Programming Algorithm for the Optimal Velocity Curve. For the above-mentioned long-distance road, 


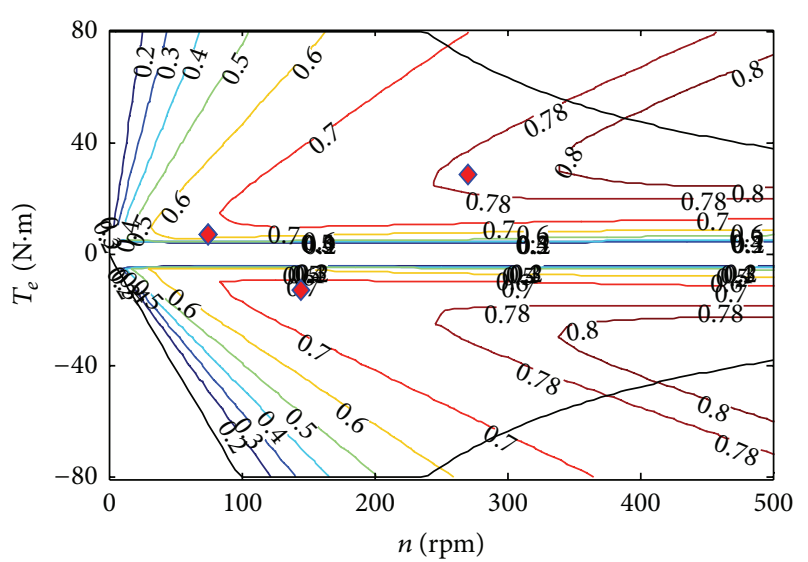

FIGURE 7: The motor operating points for different slope angle sections.

the dynamic programming (DP) algorithm [21] can accurately calculate the optimal velocity at each moment. The classic DP algorithm is used in this section to solve the global optimization problems. The distance of the road $s$ is divided into $N$ steps, and the step length is $\Delta s$. Thus, $s=N \Delta s$.

The cost function is defined as

$$
J_{v}=\sum_{k=1}^{N} E_{k}
$$

where $E_{k}$ is the $k$-step energy consumption and is given by

$$
E_{k}=\frac{2 \Delta s}{\left(v_{k}+v_{k+1}\right)} \cdot P_{\mathrm{bat} k},
$$

where $v_{k}$ is the $k$-step velocity of EV in units of $\mathrm{m} \cdot \mathrm{s}^{-1}$ and is the system state transition variable. $P_{\text {batk }}$ is the $k$-step battery power.

The system constraints are as follows:

$$
T_{\text {ebm }} \leq T_{e k} \leq T_{\text {edm }},
$$

where $T_{e k}$ is the system control variable.

The system discrete state transition model is as follows:

$$
v_{k+1}=\sqrt{v_{k}^{2}+2 a_{k} \Delta s},
$$

where $a_{k}$ is the acceleration of the EV and is described by

$$
\begin{aligned}
& a_{k} \\
& =\frac{1}{\delta m}\left(\frac{T_{e k} i_{g} i_{0} \eta_{T}}{r}-G f \cos \alpha_{k}-\frac{1}{2} C_{D} A \rho v_{k}^{2}-G \sin \alpha_{k}\right) .
\end{aligned}
$$

The solution to the dynamic programming problem can be expressed as follows.

(1) Obtain the optimal solution of the last step $J_{v, N-1}^{*}$. $J_{v, N-1}^{*}$ is the optimal energy consumption at the last
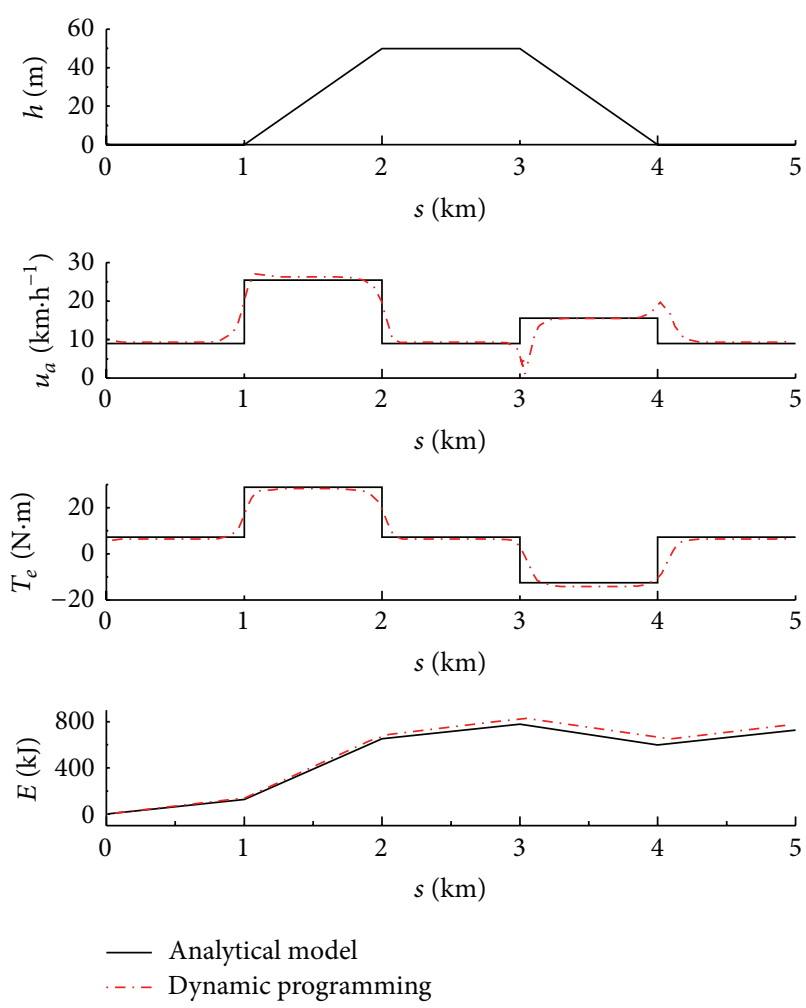

Figure 8: Optimal operating conditions solved by DP.

step $(N-1$ step), which is the function of the system state variable $v_{N-1}$ :

$J_{v, N-1}^{*}\left(v_{N-1}\right)=\min _{T_{e, N-1} \in\left[T_{\mathrm{ebm}}, T_{\mathrm{edm}}\right]}\left\{J_{v, N-1}^{*}\left(v_{N-1}, T_{e, N-1}\right)\right\}$.

Meanwhile, the optimal system control variable $T_{e, N-1}^{*}$ corresponding to the system state variable can also be obtained:

$$
T_{e, N-1}^{*}=T_{e, N-1}^{*}\left(v_{N-1}\right) .
$$

(2) Derive in reverse and obtain the optimal solution $J_{v, k}^{*}\left(v_{k}\right)$ and optimal control variable $T_{e, k}^{*}\left(v_{k}\right)$ at $k=$ $N-2, \ldots, 0$ :

$$
J_{v, k}^{*}\left(v_{k}\right)=\min _{T_{e, k} \in\left[T_{\mathrm{ebm}}, T_{\mathrm{edm}}\right]}\left\{J_{v, k}^{*}\left(v_{k}, T_{e, k}\right)\right\},
$$

where $v_{k+1}$ is deduced by $v_{k}$ according to (33).

After the backwards solution procedure is complete, the optimal objective function $J_{v, k}^{*}\left(v_{k}\right)$ and the optimal control variable $T_{e, k}^{*}\left(v_{k}\right)$ for each system state can be obtained. Then, according to the initial state $v_{0}$, combined with the system state transition equation, the optimal control variable and the corresponding system state at all steps can be solved.

According to the above equation, the optimal velocity calculated by the DP algorithm is shown in Figure 8 . The torque curve solved by the DP algorithm is very smooth. When 


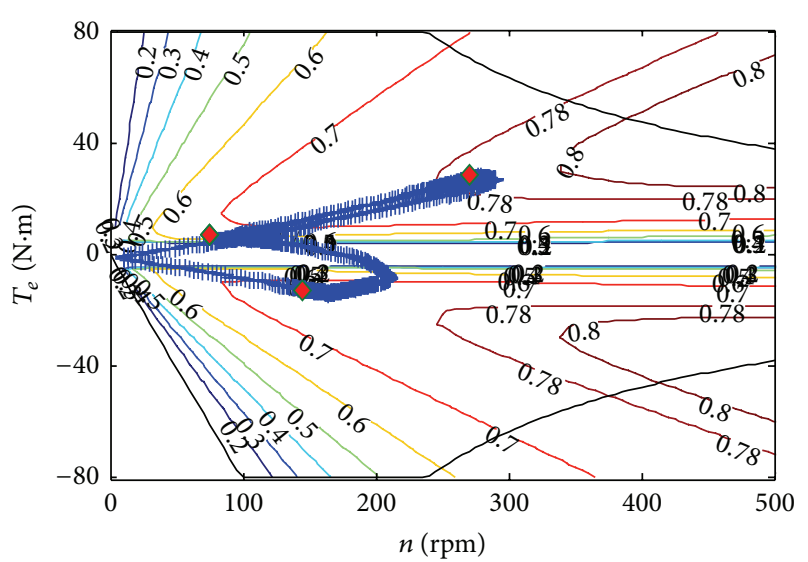

FIGURE 9: The motor operating points solved by DP.

the slope angle is increasing, the motor torque increases in advance, and the EV begins to accelerate. When the slope angle is decreasing, the motor torque decreases in advance, and the EV begins to decelerate. The energy consumption calculated by the DP algorithm is close to the ideal result calculated by the analytical approach.

Figure 8 shows that the DP algorithm can accurately solve the system dynamic process compared with the analytical approach. The optimal velocities solved by both the analytical approach and the DP algorithm in the steady state are the same, which indicates that the analytical approach can be used to solve the optimal velocity in the steady state both rapidly and accurately.

The motor operating points calculated by DP are shown in Figure 9. In the steady state, the operating area is concentrated in three points calculated by the analytical method. In the dynamic programming (DP) algorithm, the operating area is concentrated in a few lines between the three points. The reason is that the DP algorithm can handle the dynamic process, but the analytical method does not work in this condition. Considering the road load, the solving motor operating points are also under the optimal motor efficiency lines. Thus, the optimal motor efficient operation cannot achieve the energy efficient vehicle travelling.

\subsection{Dynamic Programming Algorithm for the Optimal Velocity} Curve with a Velocity Constraint. In the optimal velocity analysis, if the driver has a minimum velocity requirement, a minimum velocity constraint is added to the above considerations. The system constraint expression is changed to

$$
\begin{gathered}
T_{\mathrm{ebm}} \leq T_{e k} \leq T_{\mathrm{edm}}, \\
v_{k} \geq v_{L},
\end{gathered}
$$

where $v_{L}=20 \mathrm{~km} \cdot \mathrm{h}^{-1}$ is given as the minimum velocity limit.

The solution is similar to that in Section 4.2, and the optimal velocity curve with velocity constraint solved by the DP algorithm is shown in Figure 10.

In Figure 10, the optimal velocity is the same as that calculated in Figure 8 if the velocity is higher than $v_{L}$. If the
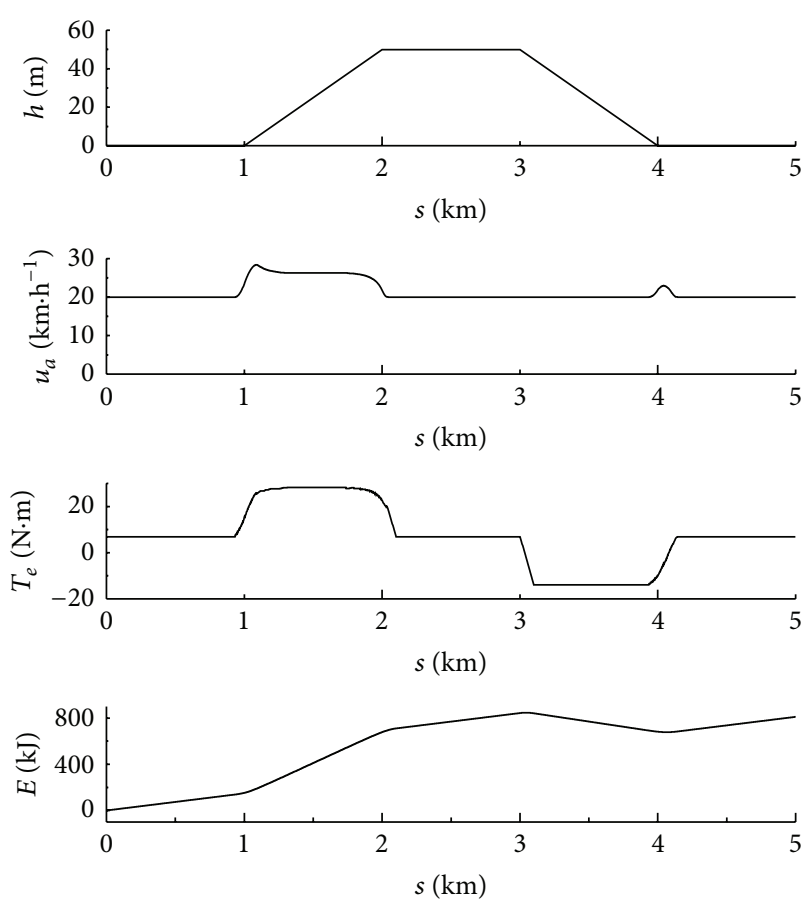

FIGURE 10: Optimal operating conditions with a velocity constraint.

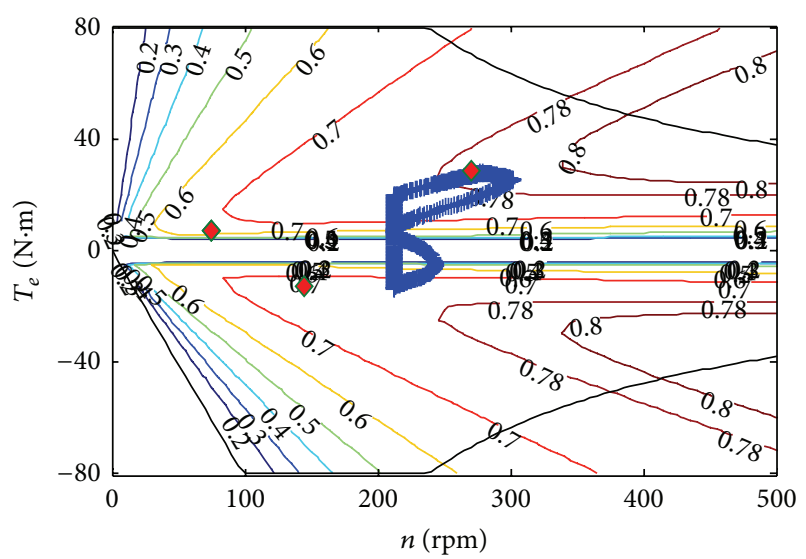

FIGURE 11: The motor operating points with a velocity constraint.

velocity is lower than $v_{L}$ in Figure 8 , it will equal $v_{L}$ when the velocity constraint is added. This finding coincides with the conclusion deduced in Section 3: on both sides of the optimal velocity, the energy consumption is increasing.

The motor operating points calculated by DP with the minimum velocity constraint are shown in Figure 11 . The motor operating area is concentrated in a few lines at the right side of the minimum velocity.

4.4. Dynamic Programming Algorithm for the Optimal Velocity Curve with a Time Constraint. In the optimal velocity analysis, if the driver has a minimum time requirement, a time 
constraint is added to the above considerations. The system constraint expression is changed to

$$
\begin{gathered}
T_{\mathrm{ebm}} \leq T_{e k} \leq T_{\mathrm{edm}}, \\
t_{\min } \leq t \leq t_{\max },
\end{gathered}
$$

where $t$ is given as the travelling time.

There are two system discrete states: velocity and time. It is a two-dimensional dynamic programming problem.

The system discrete state transition model is as follows:

$$
\begin{gathered}
v_{k+1}=\sqrt{v_{k}^{2}+2 a_{k} \Delta s}, \\
t_{k+1}=t_{k}+\frac{\Delta s}{v_{k}},
\end{gathered}
$$

where $v_{k}$ is the $k$-step velocity of EV in units of $\mathrm{m} \cdot \mathrm{s}^{-1}$ and $t_{k}$ is the $k$-step time.

The solution of the two-dimensional dynamic programming problem can be expressed as follows.

(1) Obtain the optimal solution of the last step $J_{v, N-1}^{*}$. $J_{v, N-1}^{*}$ is the optimal energy consumption at the last step ( $N-1$ step), which is the function of the system state variables $v_{N-1}$ and $t_{N-1}$ :

$$
\begin{aligned}
& J_{v, N-1}^{*}\left(v_{N-1}, t_{N-1}\right) \\
& \quad=\min _{T_{e, N-1} \in\left[T_{\text {ebm }}, T_{\text {edm }}\right]}\left\{J_{v, N-1}^{*}\left(v_{N-1}, t_{N-1}, T_{e, N-1}\right)\right\} .
\end{aligned}
$$

Meanwhile, the optimal system control variable $T_{e, N-1}^{*}$ corresponding to the system state variables can also be obtained:

$$
T_{e, N-1}^{*}=T_{e, N-1}^{*}\left(v_{N-1}, t_{N-1}\right) .
$$

(2) Derive in reverse and obtain the optimal solution $J_{v, k}^{*}\left(v_{k}, t_{k}\right)$ and optimal control variable $T_{e, k}^{*}\left(v_{k}, t_{k}\right)$ at $k=N-2, \ldots, 0$ :

$J_{v, k}^{*}\left(v_{k}, t_{k}\right)=\min _{T_{e, k} \in\left[T_{\mathrm{ebm}}, T_{\mathrm{edm}}\right]}\left\{J_{v, k}^{*}\left(v_{k}, t_{k}, T_{e, k}\right)\right\}$,

where $\left[v_{k+1}, t_{k+1}\right]$ is deduced by $\left[v_{k}, t_{k}\right]$ according to (40).

At each step of the DP algorithm, the objective function for all states $\left[v_{k}, t_{k}\right]$ under the control variable $T_{e, k}$ is calculated, which produces an unreasonable amount of system states and control variables and requires a lot of computing time. The amount of computation can be reduced by eliminating the unreasonable system states and control variables. To compare with the results in Section 4.3, the time constraint is defined as $840 \mathrm{~s} \leq t \leq 860 \mathrm{~s}$. The optimal velocity curve with the time constraint solved by the DP algorithm is shown in Figure 12, the shape of which is similar to that in Figure 8.

The motor operating points calculated by DP with the time constraint are shown in Figure 13. The operation area of the motor has more freedom than in Figure 11. Thus, it will be more energy efficient. The operating lines are in a higher velocity area compared to the results in Section 4.2 because of the shorter time constraint.
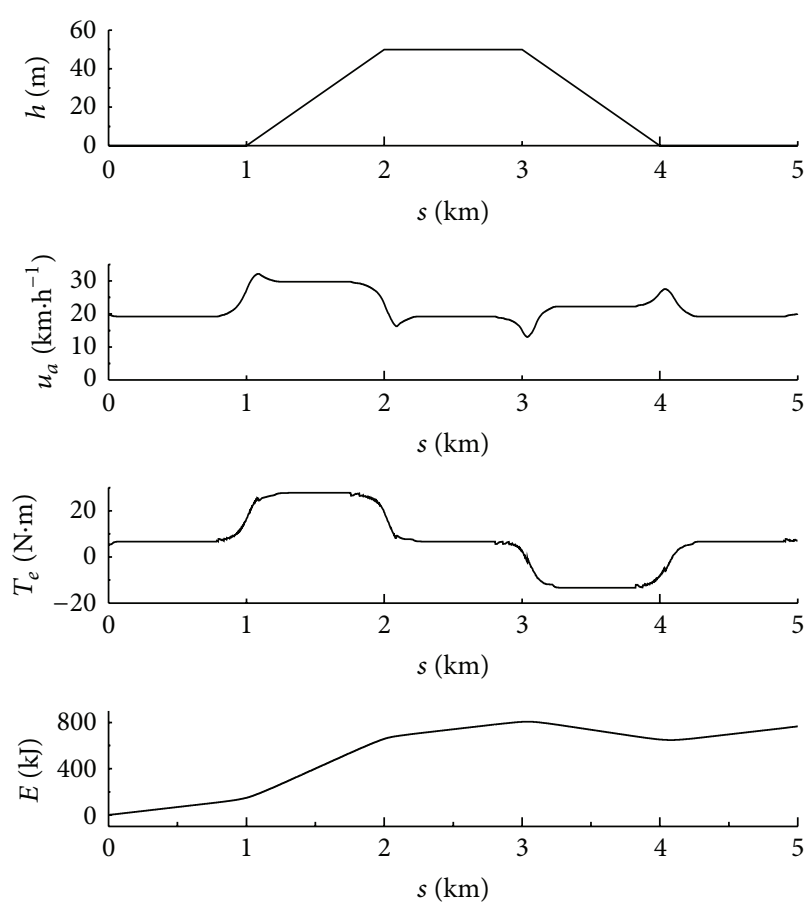

FIGURE 12: Optimal operating conditions with a time constraint.

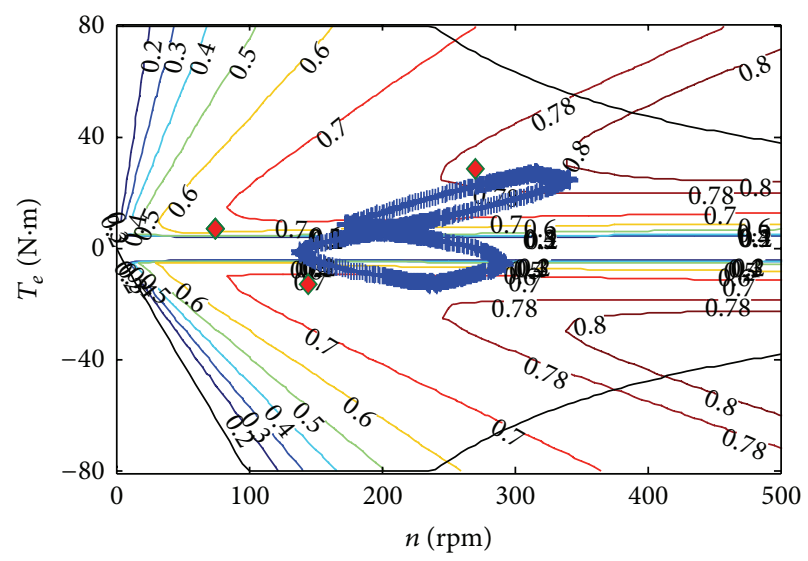

FIGURE 13: The motor operating points with a time constraint.

\section{Simulation and Experimental Results}

The EV used in the simulation and experiment is a four-wheel direct drive electric vehicle, as shown in Figure 14. The vehicle dynamics parameters of the EV are shown in Table 1.

The four hub motors are surface permanent magnet synchronous motors. The motor parameters are shown in Table 2.

The inverter is a three-phase full-bridge circuit, which is composed of MOSFETs and antiparallel diodes. The inverter parameters are shown in Table 3.

5.1. Simulation Analysis Based on MATLAB/Simulink. The EV and SPMSM model is built in MATLAB/Simulink. The road conditions in the simulation are the same as those in 


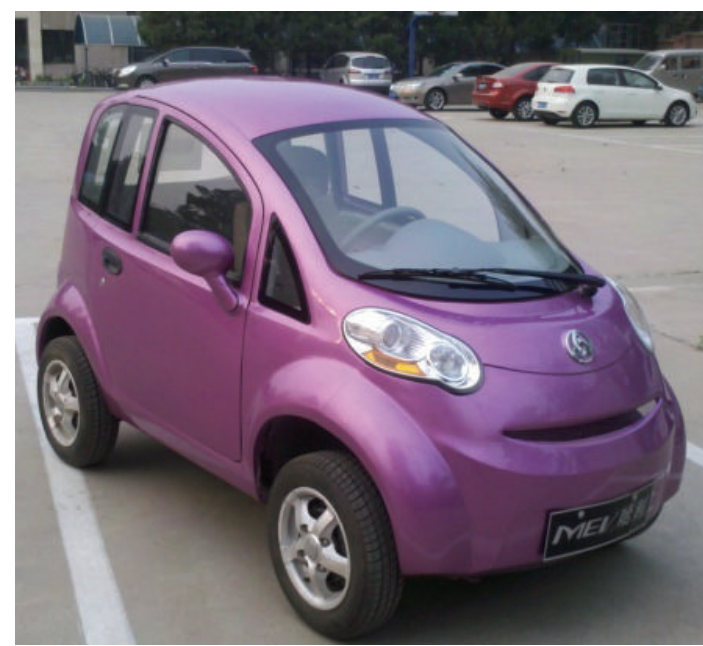

FIGURE 14: Four-wheel drive electric vehicle.

TABle 1: Parameters of the electric vehicle and battery.

\begin{tabular}{lc}
\hline Vehicle parameters & Values \\
\hline Curb weight $(\mathrm{kg})$ & 660 \\
Wheel radius $(\mathrm{m})$ & 0.25 \\
Frontal area $\left(\mathrm{m}^{2}\right)$ & 1.4 \\
Dimensionless coefficient & 0.4 \\
Rolling resistance coefficient & 0.014 \\
Battery voltage $(\mathrm{V})$ & 53 \\
Battery rated capacity $(\mathrm{Ah})$ & 100 \\
Battery resistance $(\Omega)$ & 0.018 \\
\hline
\end{tabular}

TABLE 2: Specifications of the surface permanent magnet synchronous motor.

\begin{tabular}{lc}
\hline Motor parameters & Values \\
\hline Rated phase voltage $(\mathrm{V})$ & 21.6 \\
Rated phase current $(\mathrm{A})$ & 30 \\
Rated speed $\left(\mathrm{r} \cdot \mathrm{min}^{-1}\right)$ & 500 \\
Rated torque $(\mathrm{N} \cdot \mathrm{m})$ & 30 \\
Pole pairs & 23 \\
Armature resistance $(\Omega)$ & 0.031 \\
$d$-axis inductance $(\mathrm{H})$ & $7.6 \times 10^{-5}$ \\
-axis inductance $(\mathrm{H})$ & $7.6 \times 10^{-5}$ \\
Magnet flux-linkage $(\mathrm{Wb})$ & 0.0204 \\
Iron consumption resistance $(\Omega)$ & $0.006 \omega+1.5$ \\
\hline
\end{tabular}

Section 4 . The DP algorithm, $10 \mathrm{~km} \cdot \mathrm{h}^{-1}$ constant velocity, $20 \mathrm{~km} \cdot \mathrm{h}^{-1}$ constant velocity, $30 \mathrm{~km} \cdot \mathrm{h}^{-1}$ constant velocity, and $40 \mathrm{~km} \cdot \mathrm{h}^{-1}$ constant velocity are compared for motor torque and energy consumption, as shown in Figure 15.

As shown in Figure 15, the lower the velocity is, the less the electromagnetic torque is demanded. The energy consumption is not less with decreased speed, which is mainly related to the motor operating points. In the five conditions, the energy consumption when traveling the distance $s$ is shown in Table 4.
TABLE 3: Specifications of the inverter.

\begin{tabular}{lc}
\hline Motor parameters & Values \\
\hline MOSFET resistance $(\Omega)$ & $5.6 \times 10^{-3}$ \\
Diode resistance $(\Omega)$ & $1 \times 10^{-4}$ \\
Diode on-state voltage $(\mathrm{V})$ & 1.3 \\
MOSFET parallel number & 4 \\
\hline
\end{tabular}
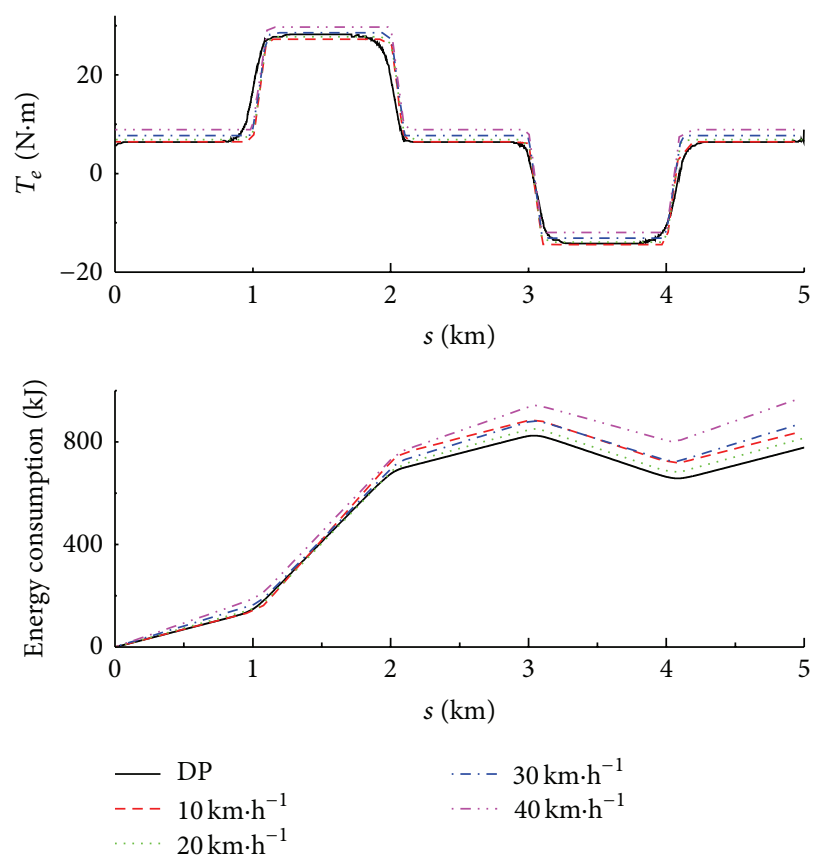

FIGURE 15: Electromagnetic torque and energy consumption in different conditions.

TABle 4: Consumption energy in distance $s$.

\begin{tabular}{lcc}
\hline Conditions & Time $(\mathrm{s})$ & Energy consumption $(\mathrm{kJ})$ \\
\hline $10 \mathrm{~km} \cdot \mathrm{h}^{-1}$ & 1800 & 843.21 \\
$20 \mathrm{~km} \cdot \mathrm{h}^{-1}$ & 900 & 815.47 \\
$30 \mathrm{~km} \cdot \mathrm{h}^{-1}$ & 600 & 875.21 \\
$40 \mathrm{~km} \cdot \mathrm{h}^{-1}$ & 450 & 975.61 \\
$\mathrm{DP}$ & 1490 & 753.6 \\
\hline
\end{tabular}

As shown in Table 4, the energy consumption is the lowest when the vehicle drives in accordance with the optimal velocity obtained by the DP algorithm. Compared to the $20 \mathrm{~km} \cdot \mathrm{h}^{-1}$ constant speed driving, the energy consumption for the DP algorithm is a $4.6 \%$ reduction. Therefore, the optimal mileage can be realized if the vehicle drives in accordance with the optimal velocity obtained by the DP algorithm.

Based on the above road conditions, the optimal velocity controls with and without constraints, including a velocity constraint $\left(20 \mathrm{~km} \cdot \mathrm{h}^{-1}\right)$ and a time constraint (840-860 s), are shown in Figure 16. The corresponding energy consumptions with a velocity constraint and a time constraint are shown in Table 5. 

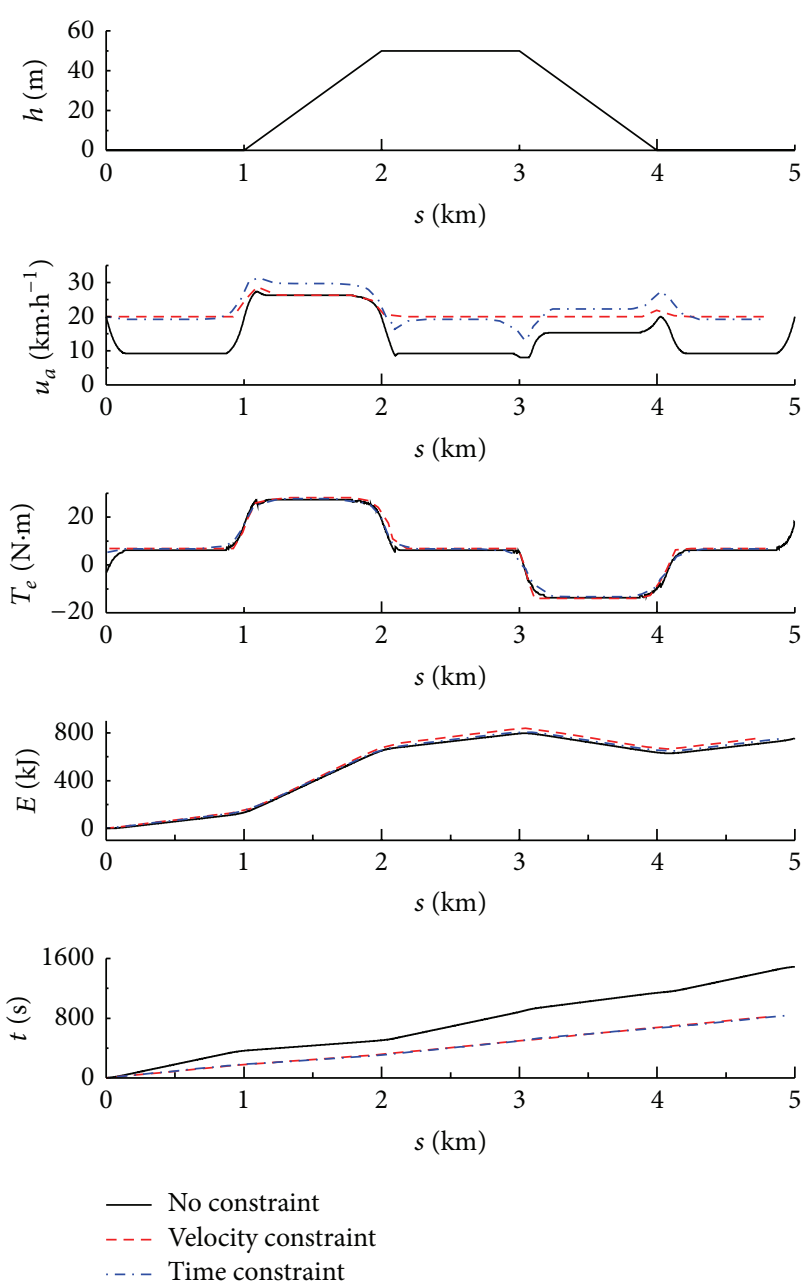

Figure 16: Optimal operating conditions with and without constraints.

TABLE 5: Consumption energy with velocity and time constraints.

\begin{tabular}{lcc}
\hline Conditions & Time (s) & $\begin{array}{c}\text { Energy consumption } \\
(\mathrm{kJ})\end{array}$ \\
\hline Velocity constraint $20 \mathrm{~km} \cdot \mathrm{h}^{-1}$ & 854 & 791.6 \\
Time constraint $840 \mathrm{~s}-860 \mathrm{~s}$ & 848 & 766.5 \\
\hline
\end{tabular}

In the case of a minimum velocity constraint of $20 \mathrm{~km} \cdot \mathrm{h}^{-1}$, the energy consumption obtained by the DP algorithm is $791.6 \mathrm{~kJ}$, which is less than that of the $10 \mathrm{~km} \cdot \mathrm{h}^{-1}$ constant speed and the $20 \mathrm{~km} \cdot \mathrm{h}^{-1}$ constant speed driving. The time consumption is $854 \mathrm{~s}$, which is also less than that of the $10 \mathrm{~km} \cdot \mathrm{h}^{-1}$ constant speed and the $20 \mathrm{~km} \cdot \mathrm{h}^{-1}$ constant speed driving. This result indicates that the velocity obtained by the DP algorithm can save energy and time simultaneously. It also achieves the minimum energy consumption control.

In the case of a time constraint, the energy consumption is $766.5 \mathrm{~kJ}$, and the time consumption is $848 \mathrm{~s}$. Compared with that in the velocity constraint, the energy consumption in the time constraint is a $3.17 \%$ reduction because the motor operation area selection has more freedom.

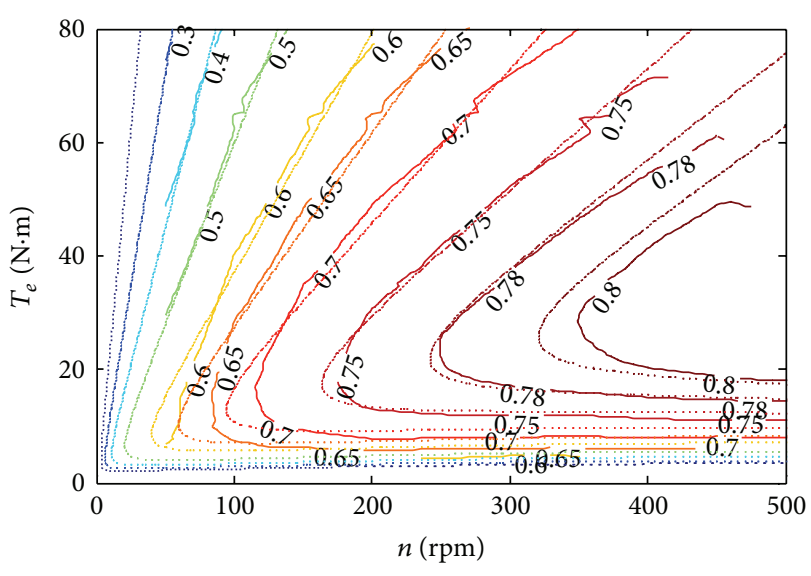

(a) Measured

o. Calculated

(a)

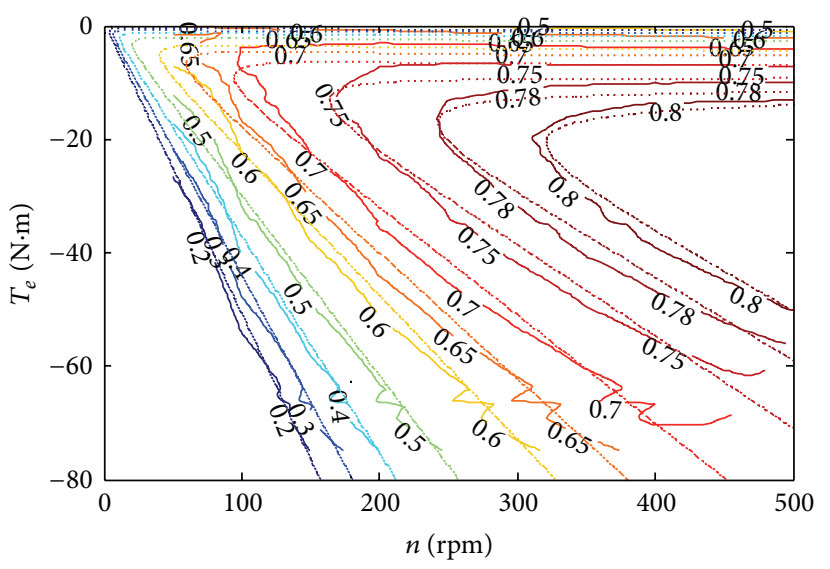

(a) Measured

o. Calculated

(b)

FIGURE 17: Motor and inverter efficiency map in driving and braking modes. (a) Driving mode. (b) Braking mode.

5.2. Experimental Results. The motor and inverter efficiency model is verified first. Figures 17(a) and 17(b) show the motor and inverter efficiency calculated by the analytical model and the experimental data in driving and braking modes, respectively. The figure indicates that the motor and inverter efficiency calculated by the analytical model can reflect the actual motor efficiency.

The test road consists of a level section $(200 \mathrm{~m})$ and an uphill section $(150 \mathrm{~m})$ with a $5 \%$ slope angle. The dynamometer is used to simulate the vehicle and the road load torque according to the vehicle dynamics parameters, and the traction motor, the inverter, and the battery are to simulate the vehicle driving system. The motor is controlled by the inverter with a reference curve of speed versus time. The dynamometer is controlled with a reference curve of torque versus time. The motor speed curve is obtained by the DP algorithm or constant velocities. The dynamometer torque 
TABLE 6: Energy consumption on the test road.

\begin{tabular}{lc}
\hline Conditions & Energy consumption $(\mathrm{kJ})$ \\
\hline $10 \mathrm{~km} \cdot \mathrm{h}^{-1}$ & 120.2 \\
$20 \mathrm{~km} \cdot \mathrm{h}^{-1}$ & 113.8 \\
$30 \mathrm{~km} \cdot \mathrm{h}^{-1}$ & 121.5 \\
$40 \mathrm{~km} \cdot \mathrm{h}^{-1}$ & 132.3 \\
$\mathrm{DP}$ & 105.4 \\
\hline
\end{tabular}

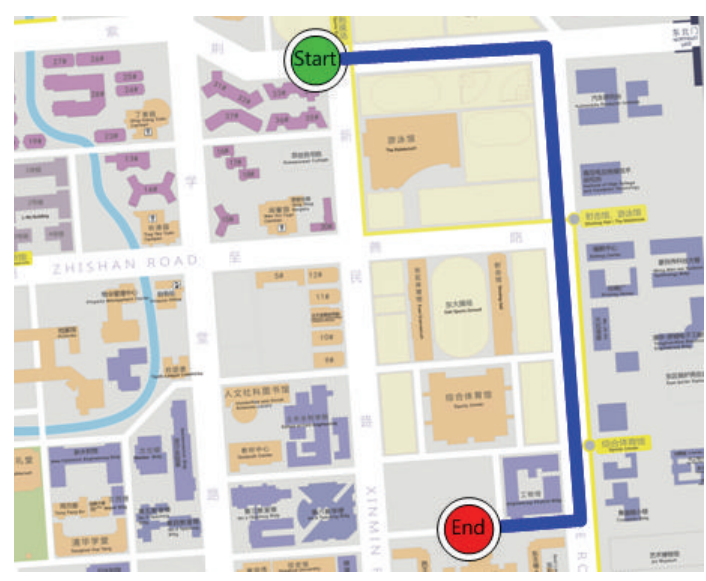

Figure 18: Test road in Tsinghua University.

curve is obtained by the road load, the vehicle dynamics parameters, and the motor or vehicle speed. They are both offline calculated. The DP algorithm, $10 \mathrm{~km} \cdot \mathrm{h}^{-1}$ constant velocity, $20 \mathrm{~km} \cdot \mathrm{h}^{-1}$ constant velocity, $30 \mathrm{~km} \cdot \mathrm{h}^{-1}$ constant velocity, and $40 \mathrm{~km} \cdot \mathrm{h}^{-1}$ constant velocity are compared for energy consumption, as shown in Table 6 .

As shown in Table 6, the velocity calculated by the DP algorithm is the minimum energy consumption compared with the other four conditions. Therefore, the optimal mileage can be achieved if the vehicle is driven according to the velocity calculated by the DP algorithm.

The DP algorithm is also verified by a set of real road condition tests. The test road is on the edge of the Automobile Research Institute in Tsinghua University, as shown in Figure 18. The length of the road is $800 \mathrm{~m}$. There is a crossroads at $268 \mathrm{~m}$ from the starting point and there is a traffic light here. The traffic light is green in [60 s, $90 \mathrm{~s}]$, during which the vehicle can turn right and the vehicle's maximum speed limit through the crossroads is $10 \mathrm{~km} \cdot \mathrm{h}^{-1}$. There are two deceleration zones at a distance of $412 \mathrm{~m}$ and $515 \mathrm{~m}$ from the starting point. In order to ensure the driving comfort, the vehicle speed limit through the deceleration zone is also set to $10 \mathrm{~km} \cdot \mathrm{h}^{-1}$. The road contains an uphill section $(268 \mathrm{~m})$ before the traffic lights and an uphill section $(144 \mathrm{~m})$, a downhill section $(103 \mathrm{~m})$, and an uphill section $(285 \mathrm{~m})$ after the traffic lights.

The optimal velocity calculated by DP algorithm and the velocities operated by drivers in the real road conditions are shown in Figure 19. The test results show that the vehicle operated by the optimal velocity reaches the crossroads with traffic lights at $61.2 \mathrm{~s}$ and at the speed of $10 \mathrm{~km} \cdot \mathrm{h}^{-1}$. However,
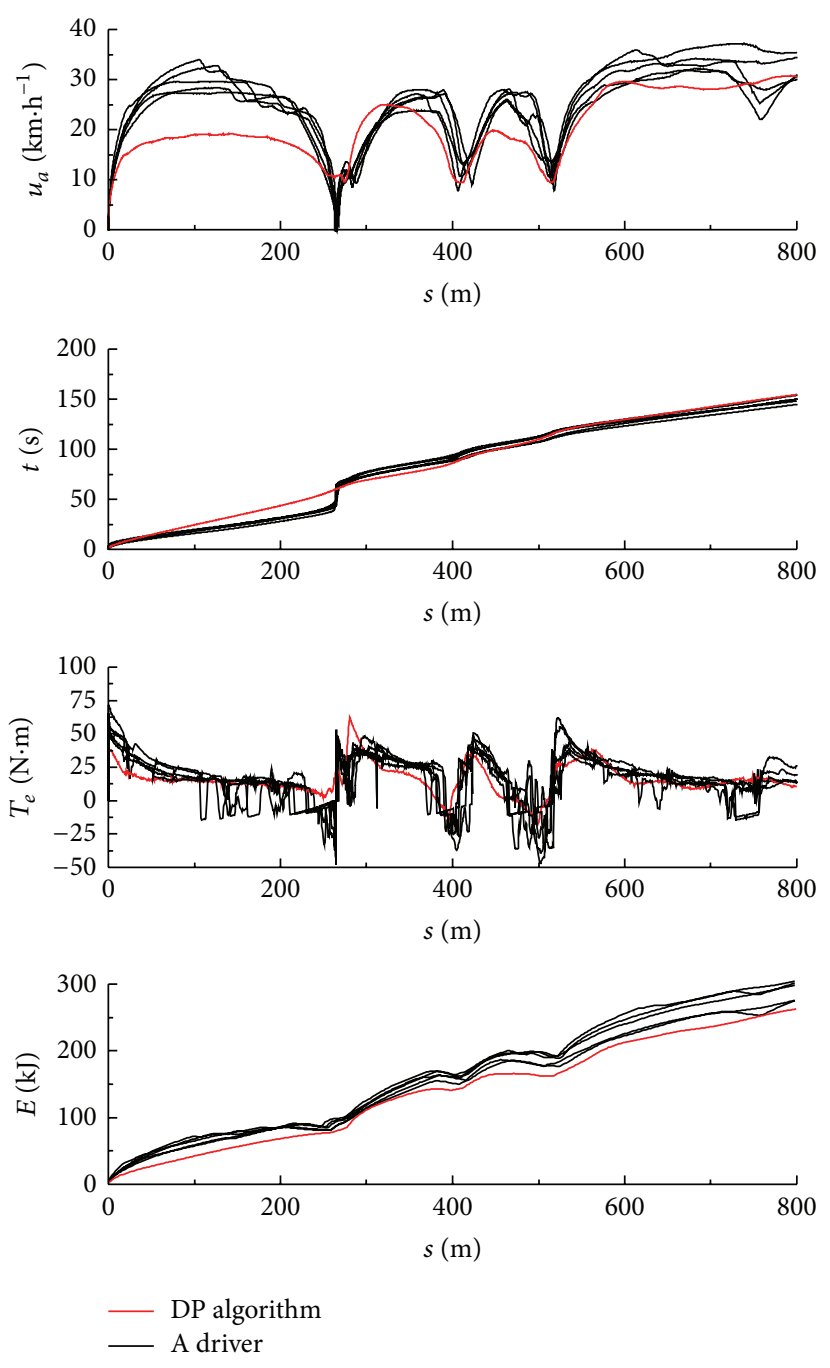

FIGURE 19: Test results in the real road conditions.

the vehicle operated by a driver is faster and arrives at the crossroads before $60 \mathrm{~s}$ and then stops to wait. After the traffic lights change to green, the vehicle starts to accelerate again. In the remaining section of the road, the torque calculated by DP algorithm is smoother than that operated by a driver. The total energy consumption operated by the optimal velocity is $262.5 \mathrm{~kJ}$, while the average of the total energy consumption operated by drivers is $290.9 \mathrm{~kJ}$. The energy consumption is reduced about $9.8 \%$.

\section{Conclusion}

It is significant to study the optimal velocity of the EV. Because the efficiency model of the electric drive system is accurate, combined with the vehicle resistance equation, the driving range formula corresponding to the vehicle torque and velocity can be obtained. To solve the analytical expression, the optimal velocity is obtained, which provides the driver with the optimal velocity reference. However, in complex road conditions, the dynamic characteristics of 
the road load need to be considered. For known road conditions, the optimal velocity curve of the drive cycle is solved by the DP algorithm. The global energy optimization can be achieved. Compared with constant velocity driving, optimal velocity travelling not only reduces energy consumption but also saves time. The conclusion is verified by comparing the DP solved velocity and other constant velocity conditions in a four-wheel drive electric vehicle.

\section{Nomenclature}

\begin{tabular}{|c|c|}
\hline A: & $\begin{array}{l}\text { Cross-sectional area exposed to flow } \\
\left(\mathrm{m}^{2}\right)\end{array}$ \\
\hline$C_{D}:$ & Dimensionless coefficient \\
\hline$C_{t}:$ & $\begin{array}{l}\text { Equivalent capacitance of RC network } \\
\text { in battery }(\mathrm{F})\end{array}$ \\
\hline $\mathrm{d} v / \mathrm{d} t:$ & Vehicle acceleration $\left(\mathrm{m} \cdot \mathrm{s}^{-2}\right)$ \\
\hline$E_{c}:$ & Regenerative energy (J) \\
\hline$E_{d}:$ & Discharged energy (J) \\
\hline$E_{k}:$ & Kinetic energy $(\mathrm{J})$ \\
\hline$f:$ & Rolling resistance coefficient \\
\hline$f_{s}:$ & Switching frequency $(\mathrm{Hz})$ \\
\hline$g:$ & $\begin{array}{l}\text { Acceleration of gravity, equal to } \\
9.8\left(\mathrm{~m} \cdot \mathrm{s}^{-2}\right)\end{array}$ \\
\hline$i_{b}:$ & Battery output current (A) \\
\hline$i_{d}:$ & $d$-axis stator current $(\mathrm{A})$ \\
\hline$i_{d i}:$ & $\begin{array}{l}\text { Equivalent } d \text {-axis iron consumption } \\
\text { current }(\mathrm{A})\end{array}$ \\
\hline$i_{d t}:$ & Equivalent $d$-axis torque current (A) \\
\hline$i_{g}:$ & Ratio of transmission \\
\hline$i_{q}:$ & $q$-axis stator current $(\mathrm{A})$ \\
\hline$i_{q i}^{i}:$ & $\begin{array}{l}\text { Equivalent } q \text {-axis iron consumption } \\
\text { current }(\mathrm{A})\end{array}$ \\
\hline$i_{q t}:$ & Equivalent $q$-axis torque current (A) \\
\hline$i_{0}:$ & Ratio of reducer \\
\hline$I:$ & Device current (A) \\
\hline$I_{m}:$ & Peak value of the sinusoidal wave (A) \\
\hline$k_{\text {on }}:$ & Turn-on energy coefficient \\
\hline$k_{\text {off }}:$ & Turn-off energy coefficient \\
\hline$L_{d}:$ & $d$-axis inductance $(\mathrm{H})$ \\
\hline$L_{q}:$ & $q$-axis inductance $(\mathrm{H})$ \\
\hline$m:$ & Mass of vehicle $(\mathrm{kg})$ \\
\hline$m_{i}:$ & Per unit fundamental stator voltage \\
\hline$n:$ & Motor speed $\left(r \cdot \min ^{-1}\right)$ \\
\hline$p:$ & Number of pole pairs \\
\hline$P_{\text {bat }}:$ & Battery input power (W) \\
\hline$P_{\text {bat } j}:$ & Battery input power in time $t_{j}(\mathrm{~W})$ \\
\hline$P_{b R}:$ & Power consumption in battery (W) \\
\hline$P_{c}:$ & $\begin{array}{l}\text { Conduction loss of the three-phase } \\
\text { inverter (W) }\end{array}$ \\
\hline$P_{c-D s}:$ & $\begin{array}{l}\text { Conduction loss of antiparallel diodes } \\
\text { in the three-phase inverter (W) }\end{array}$ \\
\hline$P_{c-\text { MOSFETs }}:$ & $\begin{array}{l}\text { Conduction loss of the MOSFETs in the } \\
\text { three-phase inverter (W) }\end{array}$ \\
\hline$P_{\mathrm{Cu}}:$ & Copper loss (W) \\
\hline$P_{e}:$ & Electromagnetic power (W) \\
\hline$P_{e n}:$ & Rated electromagnetic torque (W) \\
\hline$P_{\mathrm{Fe}}:$ & Iron loss $(\mathrm{W})$ \\
\hline
\end{tabular}

$P_{\text {in }}: \quad$ Input power $(\mathrm{W})$

$P_{\text {inv }}$ : Total loss of the three-phase inverter (W)

$P_{m}: \quad$ Mechanical loss $(\mathrm{W})$

$P_{\text {out }}: \quad$ Output power $(\mathrm{W})$

$P_{s}: \quad$ Stray loss $(\mathrm{W})$

$P_{\text {sw-on }}:$ Turn-on loss $(\mathrm{W})$

$P_{\text {sw-off: }}$ Turn-off loss (W)

$P_{\text {sw }}: \quad$ Switching loss of the three-phase inverter (W)

$R_{a}: \quad$ Armature resistance $(\Omega)$

$R_{a k}: \quad$ Resistive element of diode $(\Omega)$

$R_{d s}: \quad$ Resistive element of $\operatorname{MOSFET}(\Omega)$

$R_{s}: \quad$ Ohmic resistor in battery $(\Omega)$

$R_{t}$ : Ohmic resistor of RC network in battery $(\Omega)$

$s: \quad$ Distance $(\mathrm{m})$

$t_{c}: \quad$ Period time of the SVPWM (s)

$t_{d}: \quad$ Dead time (s)

$t_{j}: \quad$ Time in every speed step (s)

$T_{e}: \quad$ Motor electromagnetic torque $(\mathrm{N} \cdot \mathrm{m})$

$T_{e}^{*}$ : Optimum electromagnetic torque in regenerative braking $(\mathrm{N} \cdot \mathrm{m})$

$T_{\text {ebm }}$ : Maximum braking electromagnetic torque $(\mathrm{N} \cdot \mathrm{m})$

$T_{\text {edm }}$ : Maximum driving electromagnetic torque $(\mathrm{N} \cdot \mathrm{m})$

$T_{e \text { max }}$ : Maximum electromagnetic torque $(\mathrm{N} \cdot \mathrm{m})$

$T_{m}: \quad$ Motor mechanical torque $(\mathrm{N} \cdot \mathrm{m})$

$T_{t q}: \quad$ Motor output torque $(\mathrm{N} \cdot \mathrm{m})$

$u_{d}: \quad d$-axis terminal voltage $(\mathrm{V})$

$u_{q}: \quad q$-axis terminal voltage $(\mathrm{V})$

$u_{a}: \quad$ Vehicle velocity $\left(\mathrm{km} \cdot \mathrm{h}^{-1}\right)$

$v: \quad$ Vehicle velocity $\left(\mathrm{m} \cdot \mathrm{s}^{-1}\right)$

$V_{a k}: \quad$ On-state voltage drops of diode $(\mathrm{V})$

$v_{b}: \quad$ Battery output voltage $(\mathrm{V})$

$v_{c}$ : Voltage across the RC network in battery (V)

$v_{f}: \quad$ Final velocity $\left(\mathrm{m} \cdot \mathrm{s}^{-1}\right)$

$v_{0}: \quad$ Initial velocity $\left(\mathrm{m} \cdot \mathrm{s}^{-1}\right)$

$V_{d s}: \quad$ On-state voltage drops of MOSFET (V)

$V_{f}$ : Diode voltage drops at the zero-current condition (V)

$\alpha: \quad$ Slope angle (rad)

$\delta: \quad$ Vehicle rotating mass conversion factor

$\eta_{T}: \quad$ Efficiency of the transmission system

$\rho: \quad$ Air density $\left(\mathrm{kg} \cdot \mathrm{m}^{-3}\right)$

$\varphi$ : $\quad$ Load power factor angle (rad)

$\psi_{d}: \quad d$-axis stator flux-linkage $(\mathrm{Wb})$

$\psi_{f}$ : Magnet flux-linkage $(\mathrm{Wb})$

$\psi_{q}: \quad q$-axis stator flux-linkage $(\mathrm{Wb})$

$\omega$ : $\quad$ Electrical angular velocity $\left(\mathrm{rad} \cdot \mathrm{s}^{-1}\right)$.

\section{Conflict of Interests}

The authors declare that there is no conflict of interests regarding the publication of this paper.

\section{Acknowledgment}

This research is supported by the US-China Clean Energy Research Collaboration: Collaboration on Cutting-Edge 
Technology Development of Electric Vehicle (Program of International S\&T Cooperation) (no. 2010DFA72760).

\section{References}

[1] R. S. Colby and D. W. Novotny, "Efficient operation of surface mounted PM sychronous motors," IEEE Transactions on Industry Applications, vol. 23, no. 6, pp. 1048-1054, 1987.

[2] N. Urasaki, T. Senjyu, and K. Uezato, "Investigation of influences of various losses on electromagnetic torque for surfacemounted permanent magnet synchronous motors," IEEE Transactions on Power Electronics, vol. 18, no. 1, pp. 131-139, 2003.

[3] C. Mademlis, J. Xypteras, and N. Margaris, "Loss minimization in surface permanent-magnet synchronous motor drives," IEEE Transactions on Industrial Electronics, vol. 47, no. 1, pp. 115-122, 2000.

[4] H. Kim, J. Hartwig, and R. D. Lorenz, "Using on-line parameter estimation to improve efficiency of IPM machine drives," in Proceedings of the IEEE 33rd Annual Power Electronics Specialists Conference (PESC '02), pp. 815-820, June 2002.

[5] C.-C. Lin, H. Peng, J. W. Grizzle, and J.-M. Kang, "Power management strategy for a parallel hybrid electric truck," IEEE Transactions on Control Systems Technology, vol. 11, no. 6, pp. 839-849, 2003.

[6] M. Koot, J. T. B. A. Kessels, B. de Jager, W. P. M. H. Heemels, P. P. J. van den Bosch, and M. Steinbuch, "Energy management strategies for vehicular electric power systems," IEEE Transactions on Vehicular Technology, vol. 54, no. 3, pp. 771-782, 2005.

[7] V. Paladini, T. Donateo, A. de Risi, and D. Laforgia, "Supercapacitors fuel-cell hybrid electric vehicle optimization and control strategy development," Energy Conversion and Management, vol. 48, no. 11, pp. 3001-3008, 2007.

[8] S. Delprat, T. M. Guerra, G. Paganelli, J. Lauber, and M. Delhom, "Control strategy optimization for an hybrid parallel powertrain," in Proceedings of the American Control Conference, pp. 1315-1320, Arlington, Va, USA, June 2001.

[9] E. Hellström, M. Ivarsson, J. Åslund, and L. Nielsen, "Lookahead control for heavy trucks to minimize trip time and fuel consumption," Control Engineering Practice, vol. 17, no. 2, pp. 245-254, 2009.

[10] T. van Keulen, B. de Jager, D. Foster, and M. Steinbuch, "Velocity trajectory optimization in hybrid electric trucks," in Proceedings of the American Control Conference (ACC '10), pp. 5074-5079, Baltimore, Md, USA, July 2010.

[11] H. Wallentowitz, Automotive Engineering I: Longitudinal Dynamics of Vehicles, China Machine Press, 2009.

[12] N. Urasaki, T. Senjyu, and K. Uezato, "Accurate modeling for permanent magnet synchronous motor drives," in Proceedings of the 15th Annual IEEE Applied Power Electronics Conference and Exposition (APEC '00), pp. 387-392, February 2000.

[13] S. Morimoto, Y. Tong, Y. Takeda, and T. Hirasa, "Loss minimization control of permanent magnet synchronous motor drives," IEEE Transactions on Industrial Electronics, vol. 41, no. 5, pp. 511-517, 1994.

[14] J. S. Lai, R. W. Young, and J. W. McKeever, "Efficiency consideration of DC link soft-switching inverters for motor drive applications," in Proceedings of the 25th Annual IEEE Power Electronics Specialists Conference (PESC '94), vol. 2, pp. 10031010, June 1994.

[15] J. S. Lai, R. W. Young Sr., G. W. Ott, and J. W. McKeever, "Efficiency modeling and evaluation of a resonant snubber based soft-switching inverter for motor drive applications," in Proceedings of the 26th Annual IEEE Power Electronics Specialists Conference, pp. 943-949, Atlanta, Ga, USA, June 1995.

[16] W. Dong, J.-Y. Choi, Y. Li et al., "Efficiency considerations of load side soft-switching inverters for electric vehicle applications," in Proceedings of the 15th Annual IEEE Applied Power Electronics Conference and Exposition (APEC '00), pp. 10491055, New Orleans, La, USA, February 2000.

[17] D. Lu and M. Ouyang, "Torque-based optimal acceleration control for electric vehicle," Chinese Journal of Mechanical Engineering, vol. 27, no. 2, pp. 319-330, 2014.

[18] L. Benini, G. Castelli, A. Macii, E. Macii, M. Poncino, and R. Scarsi, "Discrete-time battery models for system-level lowpower design," IEEE Transactions on Very Large Scale Integration Systems, vol. 9, no. 5, pp. 630-640, 2001.

[19] L. Gao, S. Liu, and R. A. Dougal, "Dynamic lithium-ion battery model for system simulation," IEEE Transactions on Components and Packaging Technologies, vol. 25, no. 3, pp. 495505, 2002.

[20] Y.-H. Chiang, W.-Y. Sean, and J.-C. Ke, "Online estimation of internal resistance and open-circuit voltage of lithium-ion batteries in electric vehicles," Journal of Power Sources, vol. 196, no. 8, pp. 3921-3932, 2011.

[21] R. Bellman, Dynamic Programming, Princeton University Press, New Jersey, NJ, USA, 1957. 


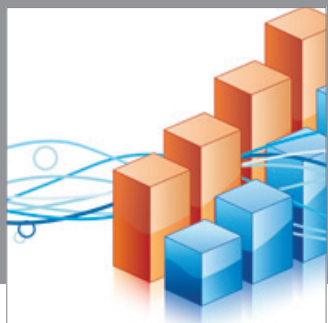

Advances in

Operations Research

mansans

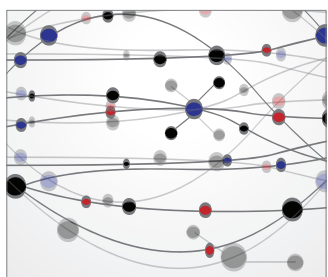

The Scientific World Journal
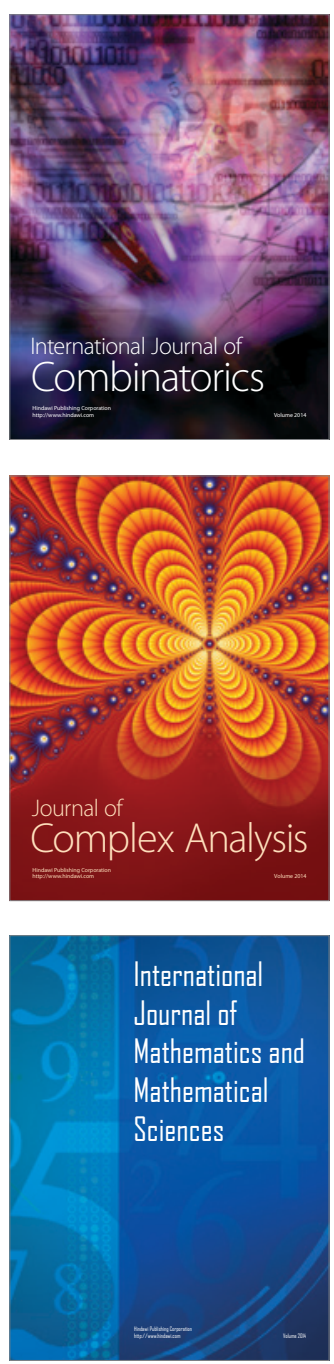
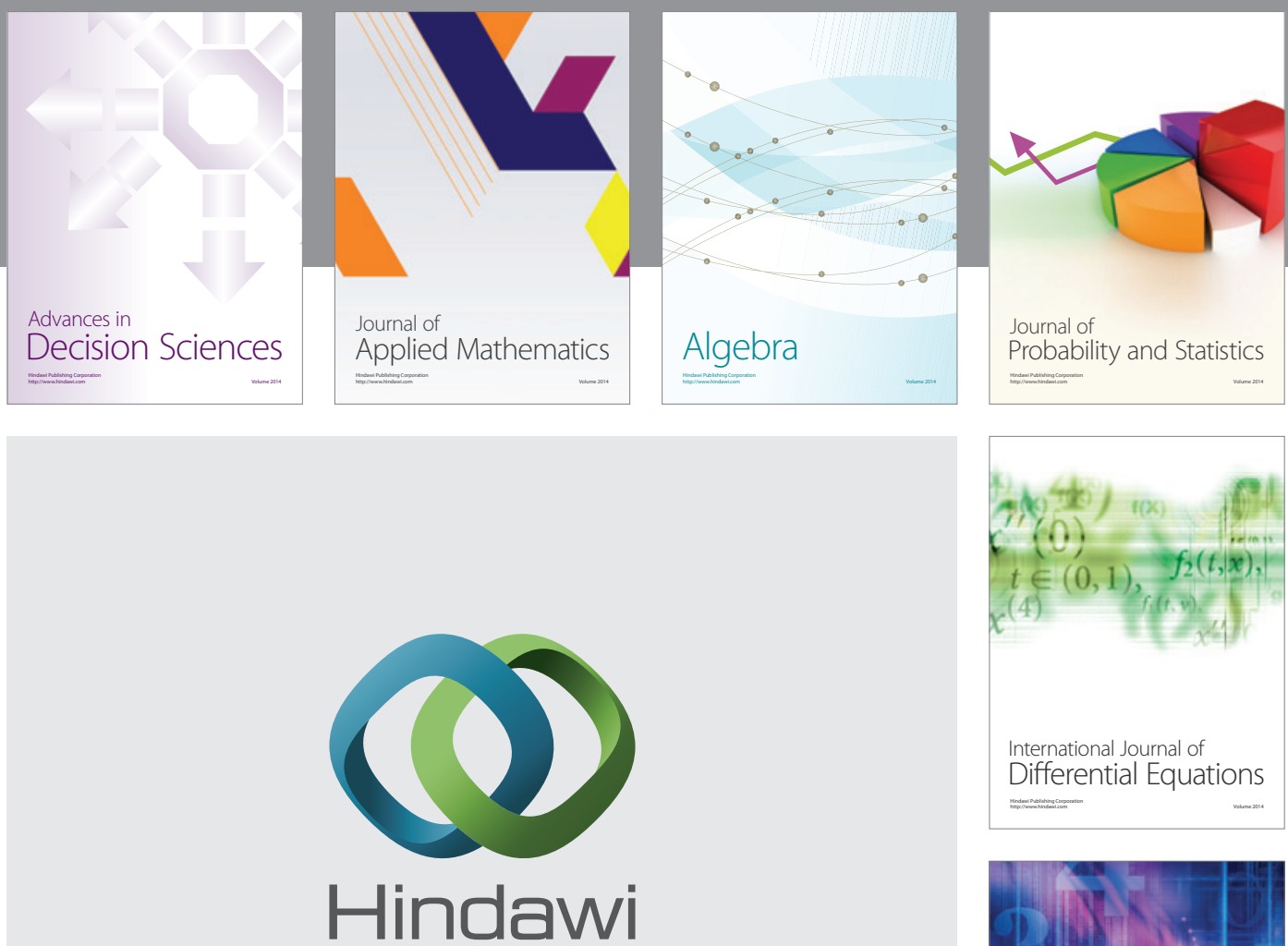

Submit your manuscripts at http://www.hindawi.com
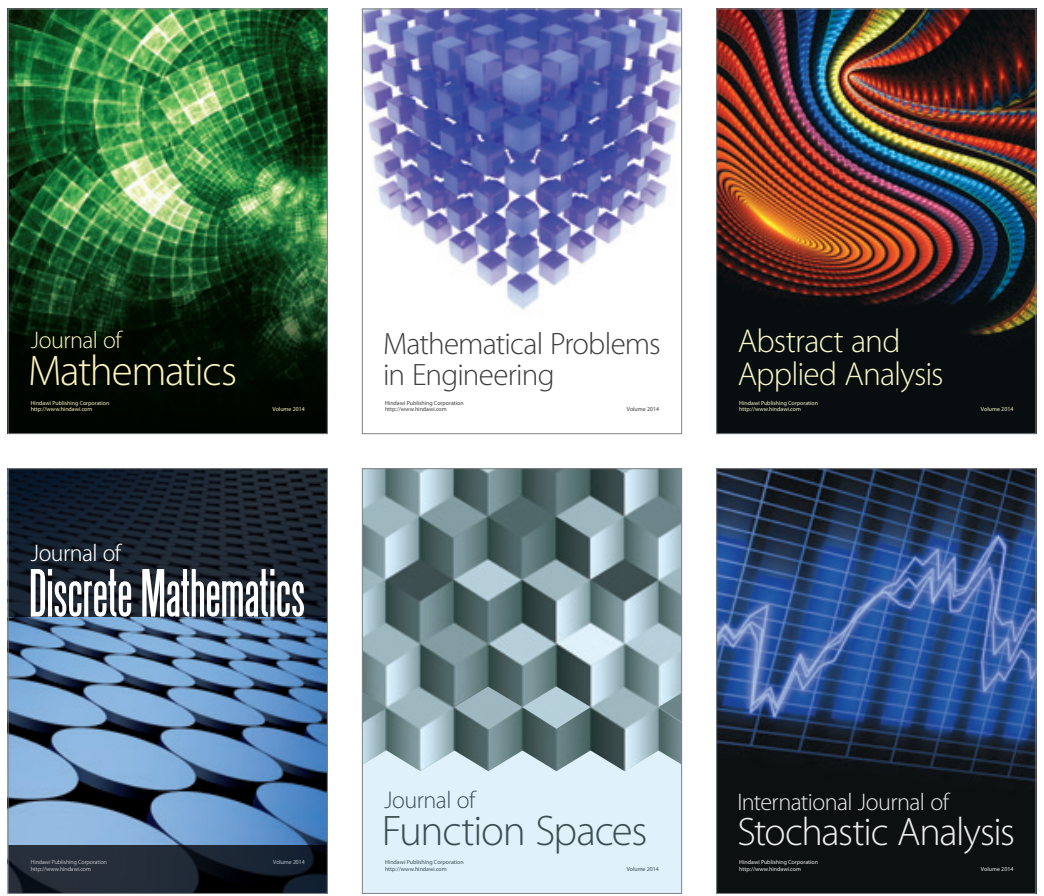

Journal of

Function Spaces

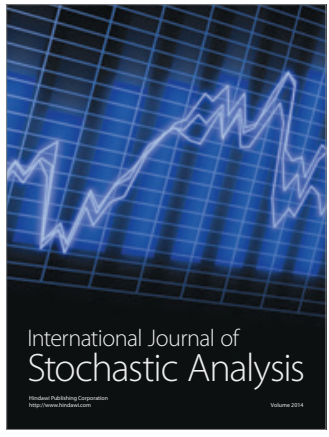

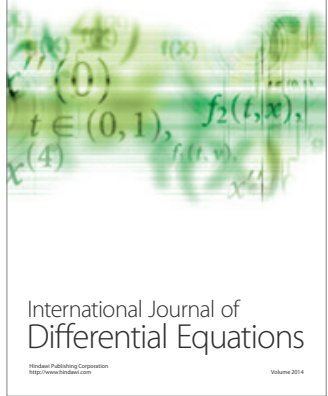
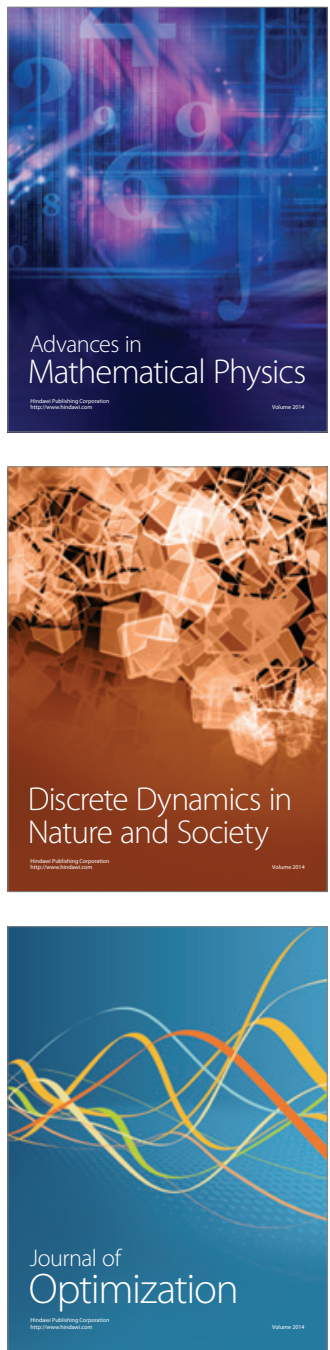